\title{
Adsorption kinetics and equilibria of two methanol samples with different water content on activated carbon
}

\author{
Meret Rösler $^{1} \cdot$ Carsten Wedler $^{1}$ (D)
}

Received: 7 May 2021 / Revised: 6 August 2021 / Accepted: 14 August 2021 / Published online: 3 September 2021

(c) The Author(s) 2021

\begin{abstract}
To investigate the influence of fluid purity on the adsorption properties, adsorption kinetics and adsorption equilibria of two methanol samples with different water content on an activated carbon were studied. The purity of the methanol samples was $98.5 \%$ and $99.9 \%$. Measurements were conducted at $298 \mathrm{~K}$ and $318 \mathrm{~K}$ using a magnetic suspension balance and cover a wide $p / p_{0}$ range. To determine effective diffusion time constants and mass transfer coefficients, adsorption kinetics were evaluated using an isothermal and a nonisothermal Fickian diffusion model, and the linear driving force model. The pressure dependence of the kinetic parameters was studied and discussed. A small influence of sample purity on the adsorption equilibria was observed, as the purer methanol sample showed slightly higher equilibrium loadings than the less pure sample. However, significantly faster adsorption kinetics were observed for the purer sample at all temperature and pressure conditions. Compared to the less pure sample, the determined effective diffusion time constants and the mass transfer coefficients were up to $98 \%$ and $35 \%$ higher, respectively.
\end{abstract}

Keywords Methanol adsorption - Methanol purity · Adsorption kinetics · Effective diffusion time constants · Mass transfer coefficients $\cdot$ Measurement uncertainty

\section{Introduction}

Adsorption properties of organic solvents are important characteristics for various applications. Since solvents are widely used in chemical industry, e.g., as basic chemicals in synthesis processes, the separation of valuable or environmentally critical gaseous solvents from exhaust gas is an indispensable process step. Through adsorption, the solvents can not only be removed from the exhaust gas stream but also be recycled at the same time [1]. In addition, solvents are used as a working fluid in adsorption refrigeration systems [2]. In both cases, adsorption equilibria and kinetics of the solvent-adsorbent system are essential information for process design. When these properties are investigated, the solvent should be used with the highest possible purity, since impurities in the solvent can influence both the adsorptive and thermophysical properties. First, the impurities can compete with the molecules of the solvent during

Carsten Wedler

c.wedler@thermo.rub.de

1 Thermodynamics, Ruhr University Bochum, 44780 Bochum, Germany adsorption, which can lead to distortion of equilibria and kinetics. Second, the impurities in the gaseous phase result in an inaccurate description of the thermophysical properties calculated with an equation of state (EOS) for the pure solvent, which can lead to an incorrect evaluation of the measurement results. Depending on the measurement principle, different thermophysical properties play a role. For example, the density of the gaseous phase $\rho_{\text {gas }}$ is required for the buoyancy correction during gravimetric adsorption measurements [3] and the compressibility [4] or the nonideality factor [5] for consideration of real gas behavior during volumetric adsorption measurements. Although it would be possible to determine the gas density using a density sinker according to the Archimedes principle directly in a gravimetric sorption system, this cannot be recommended for solvent adsorption due to the low gas densities of the solvent vapor. For gas densities much lower than $1 \mathrm{~kg} / \mathrm{m}^{3}$ (see exemplary values in Table 1), the measurement uncertainty of the density measurement would be significantly larger than the uncertainty of an appropriate EOS. Third, an inaccurately calculated value for the saturated vapor pressure $p_{0}$ results in a shifted $p / p_{0}$ plot. To show these discrepancies, the variations between pure and two methanol samples 
Table 1 Calculated gas densities and saturated vapor pressures of pure methanol and two methanol/water mixtures at temperatures of 293.15 K and 323.15 K

\begin{tabular}{llll}
\hline$T[\mathrm{~K}]$ & $\begin{array}{l}\text { Mass ratio methanol/ } \\
\text { water [wt.-\%] }\end{array}$ & $\rho_{\text {gas }}\left[\mathrm{kg} / \mathrm{m}^{3}\right]$ & $p_{0}[\mathrm{kPa}]$ \\
\hline 298.15 & $100 / 0^{\mathrm{a}}$ & 0.2250 & 16.98 \\
& $99.5 / 0.5^{\mathrm{b}}$ & $0.2209^{\mathrm{c}}$ & $16.74^{\mathrm{c}}$ \\
& $98.5 / 0.5^{\mathrm{b}}$ & $0.2128^{\mathrm{c}}$ & $16.26^{\mathrm{c}}$ \\
318.15 & $100 / 0^{\mathrm{a}}$ & 0.5614 & 44.65 \\
& $99.5 / 0.5^{\mathrm{b}}$ & $0.5519^{\mathrm{c}}$ & $44.08^{\mathrm{c}}$ \\
& $98.5 / 0.5^{\mathrm{b}}$ & $0.5331^{\mathrm{c}}$ & $42.95^{\mathrm{c}}$ \\
\hline
\end{tabular}

${ }^{\text {a }}$ Properties of the pure methanol were calculated with the EOS by de Reuck and Craven [6]

${ }^{b}$ Properties of the mixtures were calculated with the unpublished mixture model by Blackham and Lemmon as implemented in the software REFRPOP 10.0 [7]

${ }^{c}$ The values were calculated for the dew point curve of the mixture

containing water are exemplarily shown for $\rho_{\text {gas }}$ and $p_{0}$ in Table 1. For the pure methanol, the EOS by de Reuck and Craven [6] was chosen since it is the recommended EOS by the National Institute of Standard and Technology (NIST), for which the uncertainties in density and saturated vapor pressure are given as $0.1 \%$. For the impure methanol samples, the unpublished mixture model by Blackham and Lemmon as implemented in the software REFRPOP 10.0 [7] was used, for which no uncertainties are given. Deviations of up to $5 \%$ can be seen for the relevant values, leading to an inaccurate analysis of the measurement data.

Studies on the influence of impurities on the adsorption properties of $\mathrm{CO}_{2}$ or natural gas are reported in literature $[8,9]$, but to the best of our knowledge, no investigations regarding the purity of solvents as methanol or toluene were published. However, different purity grades of solvents are frequently used in literature to measure the adsorption properties. In Table 2, several literature studies on the adsorption of methanol on different adsorbents are listed. In most of the studies, methanol samples with purities between $99.5 \%$ and $99.95 \%$ were used, but in several studies, no information on the purity or the water content of the used methanol sample was given. To degas the liquid methanol sample and to remove residual air components from the methanol reservoir, an additional pretreatment of the methanol sample by several freeze-evacuate-thaw cycles was reported by Passos et al. [10] and Wu et al. [11]. From this brief overview, it becomes apparent that different purities are frequently used and traceability is not ensured in each case.

In order to show that methanol purity has an impact on the adsorption properties, the adsorption of two methanol samples with different purity on a commercial activated carbon was investigated within this study. Adsorption equilibria and kinetics were determined at temperatures of $298 \mathrm{~K}$ and $318 \mathrm{~K}$ using a magnetic suspension balance. The intention of this study is to show that it is necessary to provide accurate information about the samples used to make the experimental studies more comprehensible. Since experimental adsorption data of pure substances, e.g., are often used for multicomponent modeling [1], impurities such as water can affect the modeling results.
Table 2 A brief overview of methanol adsorption measurements in literature and their investigated methanol purity

\begin{tabular}{llll}
\hline Study & Adsorbent & Methanol purity & Investigated quantity \\
\hline Passos et al. [10] & Activated carbon & N.A. & Equilibrium \\
Bandosz et al. [44] & Activated carbon & N.A & Equilibrium \\
Linders et al. [45] & Activated carbon & N.A & Equilibrium \\
Fletcher et al. [46] & MOF & $99.9 \%$ & Equilibrium and kinetic \\
Fletcher et al. [47] & MOF & $99.9 \%$ & Equilibrium and kinetic \\
Fletcher et al. [48] & Activated carbon & $99.8 \%$ & Equilibrium and kinetic \\
Wang et al. [49] & Activated carbon & N.A & Equilibrium \\
El-Sharkawy et al. [50] & Activated carbon & $99.95 \%$ & Equilibrium \\
Henninger et al. [51] & Activated carbon & N.A & Equilibrium \\
Ushiki et al. [1] & Activated carbon & $99.7 \%$ & Equilibrium \\
Wu et al. [11] & Activated carbon & $>99.9 \%$ & Equilibrium \\
Xiao et al. [52] & Zeolite + spherical $\mathrm{Al}_{2} \mathrm{O}_{3}$ & $99.9 \%$ & Equilibrium and Kinetic \\
Gao et al. [53] & Zeolite & $99.5 \%$ & Kinetic \\
\hline
\end{tabular}

${ }^{\mathrm{a}}$ None of the authors provides information on whether mol\%, wt $\%$, vol\%, or peak area $\%$ from a GC analysis are used for purity definition

${ }^{\mathrm{b}}$ Methanol was degassed before measuring by several freeze-evacuate-thaw cycles using liquid nitrogen at $T=77.36 \mathrm{~K}$ 


\section{Materials and methods}

For the gravimetric adsorption measurements, a commercial activated carbon sample of the type "Norit ROZ3" supplied by Cabot Corporation and two different methanol samples were used. By volumetric adsorption measurements with $\mathrm{N}_{2}$ at $T=77.36 \mathrm{~K}$ and an analysis according to the theory of Brunauer et al. [12] (BET), a surface area of the activated carbon sample of $S_{\mathrm{BET}}=937.1 \mathrm{~m}^{2} / \mathrm{g}$ was determined. Assuming the Gurvich rule at a relative pressure ratio of $p / p_{0}=0.99$, a pore volume of $v_{\mathrm{BET}}=0.491 \mathrm{~cm}^{3} / \mathrm{g}$ was obtained. Volumetric $\mathrm{CO}_{2}$ measurements at $T=273.15 \mathrm{~K}$ were analyzed according to the combination of the theory of Dubinin and Astakhov [13] (DA) with the extended equation by Medek [14], for which the detailed procedure is described by Wedler and Span [15], leading to a microporous surface area of $S_{\mathrm{DA}}=661.2 \mathrm{~m}^{2} / \mathrm{g}$ and a pore volume of $v_{\mathrm{DA}}=0.457 \mathrm{~cm}^{3} / \mathrm{g}$. In addition to these classical analysis methods, nonlocal density functional theory (NLDFT) calculations were also performed to determine the surface area and the pore volume. For this purpose, the $\mathrm{CO}_{2}$ and the $\mathrm{N}_{2}$ data were analyzed simultaneously using a dual gas analysis, as recommended by Jagiello et al. [16]. The 2D-NLDFT models for porous carbonaceous materials with a heterogeneous pore surface $[17,18]$ were used, as they are implemented in the analysis tool SAIEUS by Micromeritics. This analysis has the advantage that the entire pore range can be reliably covered by the simultaneous analysis of the measurements with both gases. A surface area of $S_{\mathrm{NLDFT}}=603.5 \mathrm{~m}^{2} / \mathrm{g}$ and a pore volume of $v_{\mathrm{NLDFT}}=0.428 \mathrm{~cm}^{3} / \mathrm{g}$ were obtained, which means that the classical analysis methods might overestimate the pore structure slightly.

The two methanol samples used within this study were supplied by VWR Chemicals and their specifications are listed in Table 3. Sample 1 (M1) is a so-called anhydrous sample with a purity above $99.9 \%$, whereas sample 2 (M2) is of technical grade with a purity above $98.5 \%$. In the analysis certificate provided by the manufacturer for both samples, no information on whether the percentage values are provided in $\mathrm{mol} \%$, wt $\%$, or vol\% is given. It is only noted that the values are the result of a GC analysis. Therefore, a new GC analysis was performed, for which the samples were decanted in the way described in section 2.1. In the chromatograms, only the peaks for methanol and water were observed, from which it can be concluded that there are no other notable impurities in both samples. However, since no $100 \%$ pure methanol sample exists as a reference sample, different dilutions of methanol and water were used as references. Thus, the resulting values should be considered as an estimate rather than a true value. The estimation shows that M2 might be purer than specified by the manufacturer.

\subsection{Methanol preparation}

Before conducting the adsorption measurements, the methanol samples had to be decanted from the original glass bottle to a small stainless-steel flask, with an inner volume of $25 \mathrm{~cm}^{3}$. For both samples, different decanting and degassing procedures were applied.

Since the anhydrous sample M1 should retain a high purity to minimize the impact of impurities on the adsorption, contact of the sample with humidity in the ambient air during the process of decanting had to be prevented as far as possible. In order to avoid possible contamination, the sample was decanted within the argon atmosphere of a glove-box, which was manufactured in-house. The glove box was continuously flushed with argon and an atmosphere with a relative humidity below $5 \%$ was ensured. Beforehand, the flask was evacuated using a rotary vane pump and afterward moved into the glove-box. $20 \mathrm{~cm}^{3}$ of the sample was then filled into the flask and the flask was closed by a valve. To remove the approximately $5 \mathrm{~cm}^{3}$ of argon and other possible contaminations from the flask, the flask was successive frozen by using liquid nitrogen at $T=77.36 \mathrm{~K}$ and then evacuated for $45 \mathrm{~min}$ [19]. After the thawing of the methanol, the freeze-evacuate-thaw cycle was repeated two times.

To compare the impact of different purity of the methanol sample on the adsorption process, M2 with its lower purity was intentionally decanted at atmospheric conditions. $20 \mathrm{~cm}^{3}$ of the methanol sample M2 was filled into the flask under ambient conditions without evacuating the flask before. Consequently, an input of impurities as water from the ambient air was likely. To enable a required evacuated state in the flask for the adsorption measurement, the $5 \mathrm{~cm}^{3}$ of ambient air had to be removed from the flask. In contrast
Table 3 Methanol specifications, as they were provided by the manufacturer and estimated by a GC analysis

\begin{tabular}{llllll}
\hline & Purity manufacturer $^{\mathrm{a}}$ & $\begin{array}{l}\text { Water content } \\
\text { manufacturer }\end{array}$ & Purity estimated & $\begin{array}{l}\text { Water content } \\
\text { estimated }\end{array}$ & Purification \\
\hline Sample M1 & $>99.9 \%$ & $<0.0020 \mathrm{wt} \%$ & $99.91 \mathrm{vol} \%$ & $0.09 \mathrm{vol} \%$ & Degassed \\
Sample M2 & $>98.5 \%$ & N/A & $99.86 \mathrm{vol} \%$ & $0.14 \mathrm{vol} \%$ & None \\
\hline
\end{tabular}

${ }^{\text {a }}$ The purity was provided by the manufacturer as the result of a GC analysis without any further specification. We assume that this information is given in \% by peak area. Without further information, we cannot convert the data into $\mathrm{mol} \%$, wt $\%$, or vol\% 
to M1, the flask was directly frozen by using liquid nitrogen at $T=77.36 \mathrm{~K}$ and evacuated only once for around $5 \mathrm{~min}$.

\subsection{Gravimetric sorption system and measurement procedure}

The gravimetric sorption system shown in Fig. 1 is based on a magnetic suspension balance (ISOSORP) of Rubotherm (since 2016 TA Instruments). The mass of the permanent magnet, the lifting cage, the lifting rod, the sample container, the sample, and optionally the sinker in the measuring cell is transmitted contactless via an electromagnetic field to a microbalance, located at ambient conditions. By changing the electromagnetic field, different parts inside the measuring cell are weight: at zero point (ZP), only the permanent magnet (including the sensor core) is lifted. At measuring point 1 (MP1), the permanent magnet lifts the lifting cage, the lifting rod, and the sample container including the solid sample. At measuring point 2 (MP2), a density sinker is lifted as well. For the adsorption measurements, the difference between ZP and MP1 is relevant, whereby the masses and volumes of the individual parts should be determined beforehand in detail. The masses and volumes of these metal parts were determined by precise weighing with an analytical balance at ambient conditions and with a hydrostatic comparator, according to the principle described by McLinden and Splett [20], and are shown in Table 4. For the
Table 4 Masses and volumes of the sample (s), the sample container (c), the lifting rod (lr), and the lifting cage (lc)

\begin{tabular}{llll}
\hline$m_{\mathrm{s}}[\mathrm{g}]$ & 1.02621 & $V_{\mathrm{s}}\left[\mathrm{cm}^{3}\right]$ & 0.49936 \\
$m_{\mathrm{c}}[\mathrm{g}]$ & 2.42045 & $V_{\mathrm{c}}\left[\mathrm{cm}^{3}\right]$ & 0.30562 \\
$m_{\mathrm{lr}}[\mathrm{g}]$ & 1.07679 & $V_{\mathrm{lr}}\left[\mathrm{cm}^{3}\right]$ & 0.13551 \\
$m_{\mathrm{lc}}[\mathrm{g}]$ & 1.59176 & $V_{\mathrm{lc}}\left[\mathrm{cm}^{3}\right]$ & 0.20031 \\
\hline
\end{tabular}

adsorption measurement of saturated vapors, a vapor-liquidequilibrium (VLE) cell is temperature-controlled by a bath thermostat and the adsorption measurements are performed with the gaseous phase of the VLE. The methanol-filled stainless-steel flask described in section 2.1 was used as VLE cell. The pressure $p$ of the vapor depends on the temperature in the VLE cell. To ensure a constant temperature, the VLE cell is surrounded by a copper block in the bath. The temperature $T_{\mathrm{VLE}}$ of the copper block is measured by a resistance thermometer and is assumed to be the temperature of the VLE. The temperature of the measuring cell is controlled by an additional circulating thermostat and the gas temperature $T_{\text {ads }}$ is measured by a resistance thermometer closely to the sample container; the gas temperature is considered the adsorption temperature. To prevent possible condensation of the vapor in the piping between measuring and VLE cell, the pipes are electrically heated. For the vapor adsorption measurements, a pressure sensor with a

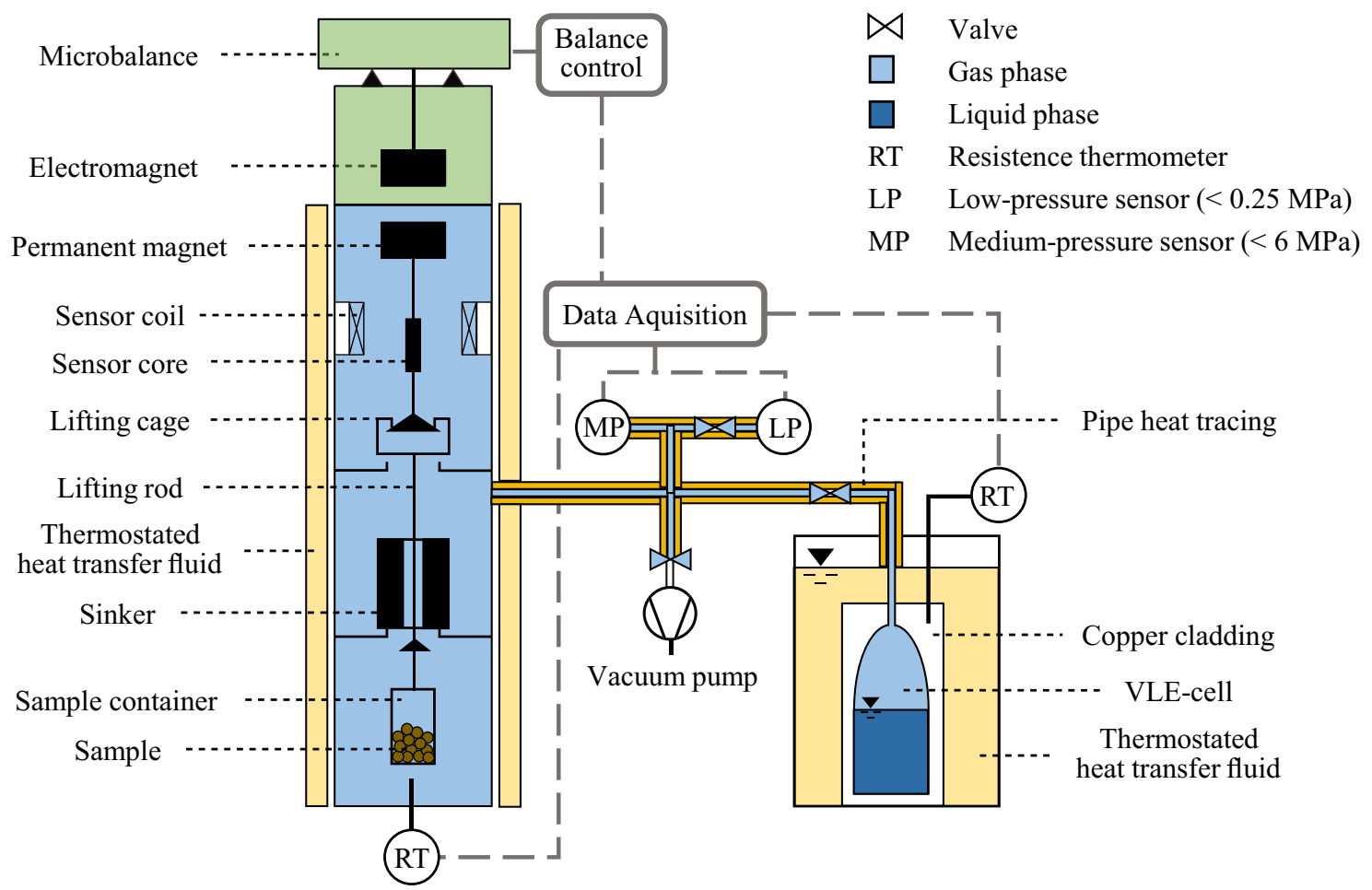

Fig. 1 Schematic of the gravimetric sorption system, shown at measuring point 1 (MP1) 
relatively low-pressure range of up to $0.25 \mathrm{MPa}$ is used. Another pressure sensor with a range of up to $6 \mathrm{MPa}$ can be used for buoyancy measurements with helium to determine the volume of the sample.

The data for adsorption equilibria and kinetics were both obtained from the same experiment. The measurements were conducted along adsorption isotherms at $298 \mathrm{~K}$ and $318 \mathrm{~K}$. Reproducibility measurements were conducted for a number of measuring points at $318 \mathrm{~K}$. The general measurement procedure was as follows: (a) the sample material was degassed at $473 \mathrm{~K}$ for $6 \mathrm{~h}$ using a rotary vane pump, (b) $T_{\text {VLE }}$ was set to $263.15 \mathrm{~K}$ and $T_{\text {ads }}$ to $298 \mathrm{~K}$ or $318 \mathrm{~K}$, while the valve (V1) between measurement cell and VLE cell was closed, (c) the sample mass $m_{\mathrm{s}}$ was determined in the evacuated measuring cell, (d) V1 was opened, the pressure in the measuring cell increased, and the adsorption kinetics were recorded with a data logging interval of $1.5 \mathrm{~s}$, (e) adsorption equilibrium has been reached and recorded, (f) V1 was closed, $T_{\text {VLE }}$ was increased (in most cases by $5 \mathrm{~K}$ ), and (g) the steps (d), (e), and (f) were repeated up to the last pressure point of the isotherm. From this cumulative measurement procedure, it becomes apparent, that the adsorption kinetics are not measured starting in an evacuated state, but are based on the previous adsorption equilibrium.

In order to determine the adsorbed mass $m_{\text {ads }}$, the mass balance of the magnetic suspension system in Eq. (1) has to be solved. For this purpose, the weighing signals $W$ in MP1 (1) and ZP (0) are measured. $m_{01}$ and $V_{01}$ are mass and volume, respectively, of the additionally lifted parts when switching from ZP to MP1: the sample (s), the sample container (c), the lifting rod (lr), and the lifting cage (lc). The volume of the sample $V_{\mathrm{s}}$ was determined by helium buoyancy measurements at pressures from (1 to 5) $\mathrm{MPa}$ and a temperature of $348 \mathrm{~K}$, for which the detailed procedure is described elsewhere [21]. The temperature of $348 \mathrm{~K}$ was chosen to minimize the possible adsorption of helium on the sample [22]. The mass of the sample $m_{\mathrm{s}}$ was measured in the gravimetric sorption system at evacuated state. The values for $V_{\mathrm{s}}$ and $m_{\mathrm{s}}$ are shown in Table 4 . For all adsorption measurements within this study, the same sample mass was used since the system was not opened during the investigations.

$$
\begin{aligned}
& \begin{array}{l}
W_{01}\left(p, T_{\mathrm{ads}}\right)=\left(m_{01}+m_{\mathrm{ads}}\left(p, T_{\mathrm{ads}}\right)-\rho_{\mathrm{gas}, \mathrm{EOS}}\left(T_{\mathrm{VLE}}\right) \cdot V_{01}\right) \\
\cdot \alpha \cdot \phi_{\mathrm{gas}, 01}\left(\rho_{\mathrm{gas}}\right)
\end{array} \\
& \begin{array}{l}
W_{01}\left(p, T_{\mathrm{ads}}\right)=W_{1}\left(p, T_{\mathrm{ads}}\right)-W_{0}\left(p, T_{\mathrm{ads}}\right) \\
m_{01}=m_{\mathrm{s}}+m_{\mathrm{c}}+m_{\mathrm{lr}}+m_{\mathrm{lc}}
\end{array} \\
& V_{01}=V_{\mathrm{s}}+V_{\mathrm{c}}+V_{\mathrm{lr}}+V_{\mathrm{lc}}
\end{aligned}
$$

To consider the buoyancy of the lifted volume $V_{01}$, the density of gaseous methanol $\rho_{\text {gas,EOS }}$ is calculated with the equation of state (EOS) by de Reuck and Craven [6] as implemented in the software package TREND 5.0 [23]. In addition, the mass balance must be corrected by the balance calibration factor $\alpha$ and the coupling factor $\phi$ considering the force transmission error (FTE) of the magnetic suspension coupling. As suggested by Kleinrahm et al. [24], a value of 1.00015 for $\alpha$ was used, which corrects the calibration of the balance in air.

\subsection{Determination of the force transmission error}

The electromagnetic field used for force transmission is influenced by the magnetic properties of the coupling house and the measuring gas, which are magnetically not entirely neutral. Therefore, the mass balance has to be corrected by the coupling factor $\phi$, considering a constant apparatus contribution $\varepsilon_{\mathrm{vac}, 01}$ and a fluid contribution $\varepsilon_{\text {fluid,01 }}$ depending on the density of the gas in the measuring cell (see Eq. 5) [24]. At evacuated state, the apparatus contribution can be determined according to Eq. (6) by weighing the well-known mass of the parts lifted between ZP and MP1, for which the balance calibration factor has to be considered as well (see Eq. 7). However, since the FTE also occurs during the determination of $m_{\mathrm{s}}$ and $V_{\mathrm{s}}, \varepsilon_{\mathrm{vac}, 01}$ and $\varepsilon_{\text {fluid,01 }}$ cannot be determined while the sample is inside of the sample container. Instead of the sample, a piece of a non-magnetic metal with a mass $m_{\mathrm{p}}$ comparable to the used sample $(\sim 1 \mathrm{~g})$ and a volume $V_{\mathrm{p}}$ was used, which was calibrated in the same way as the other metal parts.

$$
\begin{aligned}
& \phi_{\mathrm{gas}, 01}\left(\rho_{\mathrm{gas}}\right)=1+\varepsilon_{\mathrm{vac}, 01}+\varepsilon_{\mathrm{fluid}, 01}\left(\rho_{\mathrm{gas}}\right) \\
& \varepsilon_{\mathrm{vac}, 01}=\frac{m_{\mathrm{cal}, \mathrm{vac}}^{*}-m_{\mathrm{cal}}}{m_{\mathrm{cal}}} \\
& m_{\mathrm{cal}, \mathrm{vac}}^{*}=\frac{\left(W_{1}-W_{0}\right)_{\mathrm{cal}, \mathrm{vac}}}{\alpha} \\
& m_{\mathrm{cal}}=m_{\mathrm{p}}+m_{\mathrm{c}}+m_{\mathrm{lr}}+m_{\mathrm{lc}} \\
& V_{\mathrm{cal}}=V_{\mathrm{p}}+V_{\mathrm{c}}+V_{\mathrm{lr}}+V_{\mathrm{lc}}
\end{aligned}
$$

As shown in Eq. (10), the fluid contribution $\varepsilon_{\text {fluid,01 }}$ depends on an apparatus specific constant $\varepsilon_{\rho, 01}$, the density, and the magnetic susceptibility $\chi_{\mathrm{S} \text {,gas }}$ of the measuring gas. As reducing constants, $\chi_{\mathrm{S}, 0}=10^{-8} \mathrm{~m}^{3} / \mathrm{kg}$ and $\rho_{0}=1000 \mathrm{~kg} / \mathrm{m}^{3}$ have to be considered. For the diamagnetic methanol, $\chi_{\mathrm{S} \text {,gas }}=-8.39327 \times 10^{-9} \mathrm{~m}^{3} / \mathrm{kg}$ is temperature independent [25]. The apparatus-specific constant $\varepsilon_{\rho, 01}$ describes how the 
magnetic suspension coupling reacts to the magnetic susceptibility of the measuring gas. Therefore, density measurements with a strongly paramagnetic gas, as oxygen or oxygen mixtures as synthetic air, have to be performed [24]. Valves and sealings of the apparatus are not designed for pure oxygen atmospheres, thus, the measurements for this study were conducted with synthetic air. The measurements were conducted considering the substitutive metal part with known mass and volume. To determine an accurate value for $\varepsilon_{\rho, 01}$, several density measurements were conducted at pressures from (1 to 5) MPa and a temperature of $293.15 \mathrm{~K}$ and compared to the density calculated with the GERG-2008 EOS [26] as implemented in TREND 5.0 [23]. As described in Kleinrahm et al. [24], the densities as a function of $p$ and $T$ were determined according to Eq. (11). Therefore, as an initial value for $\varepsilon_{\rho, 01}$ a value given in Kleinrahm et al. [24] was assumed and the magnetic susceptibility of the paramagnetic air was calculated according to Kleinrahm et al. [24] as $\chi_{\mathrm{S} \text {,air }}=3.010 \times 10^{-7} \mathrm{~m}^{3} / \mathrm{kg}$. The deviation of the experimental density $\rho_{\text {airexp }}$ to the density calculated with GERG-2008 EOS is described by $\varepsilon_{\mathrm{fse}, 01}$ (see Eq. 12). With increasing density, $\varepsilon_{\mathrm{fse}, 01}$ increases linearly. The value for $\varepsilon_{\rho, 01}$ is then iteratively adjusted until $\varepsilon_{\mathrm{fse}, 01}(p=0 \mathrm{~Pa})=0$ since there should be no deviation to the GERG-2008 EOS at zero-density. More details about this procedure can be found in Kleinrahm et al. [24].

$\varepsilon_{\text {fluid }, 01}\left(\rho_{\text {gas }}\right)=\varepsilon_{\rho, 01} \cdot \frac{\chi_{\mathrm{S}, \text { gas }} \cdot \rho_{\text {gas }, \mathrm{EOS}}\left(T_{\mathrm{VLE}}\right)}{\chi_{\mathrm{S}, 0} \cdot \rho_{0}}$
$\rho_{\text {air }, \exp }(p, T)=\frac{m_{\mathrm{cal}, \mathrm{vac}}^{*}-\frac{W_{01}(p, T)}{\alpha}}{V_{\text {cal }}\left(1+\varepsilon_{\mathrm{vac}, 01}+\varepsilon_{\rho, 01}\left(\frac{\chi_{\mathrm{S}, \mathrm{air}}}{\chi_{\mathrm{S}, 0}}\right)\left(\frac{\rho_{\text {air,EOS }}}{\rho_{0}}-\frac{m_{\mathrm{cal}} / V_{\mathrm{cal}}}{\rho_{0}}\right)\right.}$

$\varepsilon_{\mathrm{fse}, 01}(p, T)=\frac{\rho_{\text {air,exp }}-\rho_{\text {air,EOS }}}{\rho_{\text {air,EOS }}}$

\subsection{Adsorption data evaluation}

To conduct the kinetic adsorption measurements, timedependent values have to be considered. However, it is counterproductive to switch between MP1 and ZP during the ongoing kinetic measurement since the adsorption kinetic cannot be tracked seamlessly when positions are switched. As shown in Eq. (13), the position remains constant in MP1 during the kinetic measurements and $W_{0, \text { eq }}$ is only recorded at the equilibrium state [21]. By rearranging the time-dependent mass balance in Eqs. (14), (15), the timedependent adsorbed mass $m_{\text {ads }}$ can be determined.

$W_{01}\left(p, T_{\text {ads }}, t\right)=W_{1}\left(p, T_{\text {ads }}, t\right)-W_{0, \mathrm{eq}}\left(p, T_{\text {ads }}\right)$

$W_{01}\left(p, T_{\text {ads }}, t\right)=\left(m_{01}+m_{\text {ads }}\left(p, T_{\text {ads }}, t\right)-\rho_{\text {gas, EOS }}\left(T_{\mathrm{VLE}}, t\right) \cdot V_{01}\right)$ $\cdot \alpha \cdot \phi_{\mathrm{gas}, 01}\left(\rho_{\mathrm{gas}, \mathrm{EOS}}, t\right)$

$m_{\mathrm{ads}}\left(p, T_{\mathrm{ads}}, t\right)=\frac{W_{01}\left(p, T_{\mathrm{ads}}, t\right)}{\alpha \cdot \phi_{\mathrm{gas}}\left(\rho_{\mathrm{gas}, \mathrm{EOS}}, t\right)}-m_{01}+\rho_{\mathrm{gas}, \mathrm{EOS}}\left(T_{\mathrm{VLE}}, t\right) \cdot V_{01}$

Considering the molecular mass of the adsorbed gas $M_{\text {gas }}$ and the sample mass, the time depended adsorbed loading $q$ is calculated according to Eq. (16). To describe the kinetics of the adsorption measurements, the fractional uptake $F$ is calculated according to Eq. (17) considering the timedependent loading at time $t$, the initial loading at time $t_{0}$, and the equilibrium loading $q_{\mathrm{eq}}$. For the determination of $q_{\mathrm{eq}}$, Eqs. (15), (16) were used considering the measured values when adsorption equilibrium is reached [cf. procedure step e)]

$q\left(p, T_{\mathrm{ads}}, t\right)=\frac{m_{\mathrm{ads}}\left(p, T_{\mathrm{ads}}, t\right)}{M_{\mathrm{gas}} \cdot m_{\mathrm{s}}}$

$F=\frac{q\left(p, T_{\mathrm{ads}}, t\right)-q\left(p, T_{\mathrm{ads}}, t_{0}\right)}{q_{\mathrm{eq}}\left(p, T_{\mathrm{ads}}\right)-q\left(p, T_{\mathrm{ads}}, t_{0}\right)}$

\subsection{Estimation of measurement uncertainty}

The uncertainty of the gravimetric adsorption measurements was estimated according to the "Guide of the Expression of Uncertainty in Measurements" [27]. The combined standard uncertainty $u_{\mathrm{c}}$ of the adsorption loading $q$ was calculated according to Eq. (18). As described by Yang et al. [3], the uncertainty contribution of the FTE determination is negligible. Since the measurement of $p$ and $T_{\text {ads }}$ has no direct influence on the data evaluation, their uncertainty is not considered in the estimation. Therefore, $u_{\mathrm{c}}$ depends on the standard uncertainties of the temperature measurement in the VLE cell, the calculated density, the weighing of the balance, and the lifted volumes and the masses. However, $p$ and $T_{\text {ads }}$ obviously have an influence on the adsorption loading $q\left(p, T_{\text {ads }}\right)$ and their standard uncertainty was estimated to be $u(p)=0.125 \mathrm{kPa}$ and $u\left(T_{\mathrm{ads}}\right)=0.178 \mathrm{~K}$. 
Table 5 Uncertainty budget for the relative combined standard uncertainty in adsorption loading $u_{\mathrm{c}}(q) / q$

\begin{tabular}{lll}
\hline Uncertainty contribution & Uncertainty contribution & Contribution to $u_{\mathrm{c}}(q) / q$ \\
\hline VLE temperature $T_{\mathrm{VLE}}$ & $0.069 \mathrm{~K}$ & $1.86 \cdot 10^{-6}$ \\
Density calculated with EOS $^{\mathrm{a}} \rho_{\mathrm{EOS}}$ & $0.1 \% \cdot \rho_{\mathrm{EOS}}$ & $5.04 \cdot 10^{-7}$ \\
Weighing value $^{\mathrm{b}} W_{01}$ & $60 \mu \mathrm{g}$ & $1.96 \cdot 10^{-4}$ \\
Sample volume $V_{\mathrm{s}}$ & $0.0096 \mathrm{~cm}^{3}$ & $4.25 \cdot 10^{-6}$ \\
Sample mass $m_{\mathrm{s}}$ & $0.44 \mathrm{mg}$ & $1.68 \cdot 10^{-3}$ \\
Container volume $V_{\mathrm{c}}$ & $0.0002 \mathrm{~cm}^{3}$ & $9.17 \cdot 10^{-8}$ \\
Container mass $m_{\mathrm{c}}$ & $0.22 \mathrm{mg}$ & $7.01 \cdot 10^{-4}$ \\
Lifting rod volume $V_{\mathrm{lr}}$ & $0.0002 \mathrm{~cm}^{3}$ & $8.79 \cdot 10^{-8}$ \\
Lifting rod mass $m_{\mathrm{lr}}$ & $0.21 \mathrm{mg}$ & $6.95 \cdot 10^{-4}$ \\
Lifting cage volume $V_{\mathrm{lc}}$ & $0.0003 \mathrm{~cm}^{3}$ & $1.42 \cdot 10^{-7}$ \\
Lifting cage mass $m_{\mathrm{lc}}$ & $0.22 \mathrm{mg}$ & $7.22 \cdot 10^{-4}$ \\
\hline Combined expanded uncertainty $U_{\mathrm{c}}(q)(k=2)$ & $0.0224 \mathrm{mmol} / \mathrm{g}$ & $4.17 \cdot 10^{-3}$ \\
\hline
\end{tabular}

As an example, the contributions to $U_{\mathrm{c}}(q)$ were calculated for the adsorption of the methanol sample 2 at $T_{\text {ads }}=318 \mathrm{~K}$ and $p=10.10 \mathrm{kPa}$ with $q=5.377 \mathrm{mmol} / \mathrm{g}$

${ }^{a}$ Uncertainty in density was taken as stated in de Reuck and Craven [6]

${ }^{\mathrm{b}}$ Provided by the manufacturer

$u_{c}(q)=\left[\left(\left(\frac{\partial q}{\partial T_{\mathrm{VLE}}}\right) u\left(T_{\mathrm{VLE}}\right)\right)^{2}+\left(\left(\frac{\partial q}{\partial \rho_{\mathrm{gas}, \mathrm{EOS}}}\right) u\left(\rho_{\mathrm{gas}, \mathrm{EOS}}\right)\right)^{2}+\left(\left(\frac{\partial q}{\partial V_{01}}\right) u\left(V_{01}\right)\right)^{2}+\left(\left(\frac{\partial q}{\partial m_{01}}\right) u\left(m_{01}\right)\right)^{2}+\left(\left(\frac{\partial q}{\partial W_{01}}\right) u\left(W_{01}\right)\right)^{2}\right]^{0.5}$

For the data evaluation, the individual uncertainty contributions are given in Table 5. Conducting a sensitivity analysis of the individual contributions on the adsorption loading has led to the sensitivity coefficients $\partial q / \partial x$. Under consideration of a coverage factor of $k=2$, the combined expanded uncertainty of the adsorption loading $U_{\mathrm{c}}(q)$ was determined and is exemplarily shown for the adsorption of the methanol sample 2 at $T_{\text {ads }}=318 \mathrm{~K}$ and $p=10.10 \mathrm{kPa}$ with $q=5.377 \mathrm{mmol} / \mathrm{g}$ in Table 5 . The values for the other equilibrium loadings are listed in Tables 6, 7.

\subsection{Equilibrium modeling}

The adsorption equilibria are described by using the Dubinin-Astakhov (DA) isotherm model according to Eq. (19), which considers the characteristic energy of adsorption $E$, the saturated vapor pressure $p_{0}$ at measuring temperature $T_{\text {ads }}$, the universal gas constant $R$, the Dubinin coefficient $n$, the pore volume $\nu_{0}$, and the adsorbed volume $\nu_{\text {ads }}$. The adsorbed volume can be calculated according to Eq. (20) considering the adsorbed loading and the molar density of the adsorbed phase. According to the DA theory, the density of the adsorbed phase was assumed to be the saturated-liquid density $\rho_{\mathrm{m}, \text { liq,EOS }}$ of the measuring fluid at measuring temperature. By adjusting the parameters $v_{0}$, $E$, and $n$, the best-fit values for these adjustable parameters were determined by minimizing the root mean square deviation (RMSD) between the experimental values for $\nu_{\text {ads }}$ and the modeled values from Eq. (19).

$v_{\text {ads }}\left(p, T_{\text {ads }}\right)=v_{0} \cdot \mathrm{e}^{\left[-\left(\frac{R \cdot T_{\text {ads }} \cdot \ln \left(\frac{p_{0}}{p}\right)}{E}\right)^{n}\right]}$

$v_{\mathrm{ads}}\left(p, T_{\mathrm{ads}}\right)=\frac{q_{\mathrm{eq}}\left(p, T_{\mathrm{ads}}\right)}{\rho_{\mathrm{m}, \mathrm{liq}, \mathrm{EOS}}\left(T_{\mathrm{ads}}\right)}$

The DA theory was formulated for the adsorption of pure fluids. Although a fluid as shown in Sect. 2.1 usually contains impurities, this model is used in the literature under the assumption of a pure fluid for the adsorption of solvent vapors. Therefore, it is also assumed for the modeling that pure methanol is used; thus, the EOS by de Reuck and Craven [6] is used to calculate $p_{0}$ and $\rho_{\mathrm{m}, \text { liq }}$.

\subsection{Kinetic modeling}

In order to compare the different kinetic adsorption measurements, the isothermal Fickian diffusion model (IFD) according to Eq. (21) based on Fick's second law of diffusion, the linear driving force model (LDF) according to Eq. (22), and a nonisothermal solution of Fick's second law of diffusion (NFD) according to Eq. 25 were used. The IFD model is often referred to as the formulation of [28] or Boyd et al. [29] but was also described earlier by 
Table 6 Adsorption loadings $q$ of M1 with the respective combined expanded uncertainty $U_{\mathrm{c}}$ for $k=2$

\begin{tabular}{|c|c|c|c|c|c|}
\hline$T_{\mathrm{ads}}[\mathrm{K}]$ & $T_{\mathrm{VLE}}[\mathrm{K}]$ & $p[\mathrm{kPa}]$ & $p / p_{0}{ }^{\mathrm{a}}[-]$ & $q[\mathrm{mmol} / \mathrm{g}]$ & $U_{\mathrm{c}}(q)[\mathrm{mmol} / \mathrm{g}]$ \\
\hline \multicolumn{6}{|l|}{$298 \mathrm{~K}$} \\
\hline 297.93 & 263.02 & 2.1800 & 0.130 & 5.114 & 0.022 \\
\hline 297.98 & 268.27 & 3.0570 & 0.182 & 6.572 & 0.023 \\
\hline 297.98 & 273.24 & 4.1799 & 0.248 & 7.971 & 0.023 \\
\hline 298.02 & 278.25 & 5.6582 & 0.335 & 9.205 & 0.024 \\
\hline 297.99 & 283.19 & 7.5636 & 0.449 & 10.180 & 0.024 \\
\hline 298.04 & 288.22 & 10.059 & 0.596 & 10.844 & 0.025 \\
\hline 298.04 & 293.14 & 13.191 & 0.781 & 11.265 & 0.025 \\
\hline 298.09 & 295.63 & 15.028 & 0.888 & 11.501 & 0.025 \\
\hline 298.09 & 296.63 & 15.758 & 0.931 & 11.641 & 0.025 \\
\hline \multicolumn{6}{|l|}{$318 \mathrm{~K}$} \\
\hline 317.86 & 263.20 & 2.2125 & 0.050 & 1.976 & 0.021 \\
\hline 317.83 & 268.14 & 3.0448 & 0.069 & 2.566 & 0.021 \\
\hline 317.79 & 273.21 & 4.1825 & 0.095 & 3.350 & 0.022 \\
\hline 317.80 & 278.17 & 5.6573 & 0.129 & 4.315 & 0.022 \\
\hline 317.86 & 283.26 & 7.6232 & 0.173 & 5.504 & 0.022 \\
\hline 317.81 & 288.23 & 10.106 & 0.230 & 6.795 & 0.023 \\
\hline 317.86 & 293.14 & 13.224 & 0.300 & 8.019 & 0.023 \\
\hline 317.96 & 298.17 & 17.234 & 0.389 & 9.107 & 0.024 \\
\hline 317.70 & 303.09 & 22.055 & 0.504 & 10.000 & 0.024 \\
\hline 317.99 & 308.14 & 28.214 & 0.636 & 10.604 & 0.025 \\
\hline 318.44 & 313.19 & 35.756 & 0.790 & 11.006 & 0.025 \\
\hline 318.74 & 315.61 & 39.801 & 0.868 & 11.198 & 0.025 \\
\hline 318.44 & 316.61 & 41.627 & 0.920 & 11.383 & 0.025 \\
\hline 318.59 & 317.60 & 43.541 & 0.956 & 11.614 & 0.025 \\
\hline \multicolumn{6}{|c|}{$318 \mathrm{~K}$-reproduced } \\
\hline 317.90 & 293.13 & 13.113 & 0.297 & 8.046 & 0.024 \\
\hline 317.93 & 298.13 & 17.089 & 0.386 & 9.132 & 0.024 \\
\hline 317.86 & 303.17 & 22.044 & 0.500 & 10.007 & 0.024 \\
\hline 318.00 & 308.22 & 28.223 & 0.636 & 10.625 & 0.025 \\
\hline 318.49 & 313.23 & 35.743 & 0.788 & 11.016 & 0.025 \\
\hline 318.73 & 315.62 & 39.785 & 0.868 & 11.211 & 0.025 \\
\hline
\end{tabular}

${ }^{a}$ The saturated vapor pressure $p_{0}$ was calculated for the pure methanol with $T_{\text {ads }}$ for each measuring point with the EOS byde Reuck and Craven [6]

Barrer [30]. It assumes a spherical particle with a constant radius $r$, a constant diffusion coefficient $D_{\mathrm{e}, \text { IFD }}$, and that the heat of adsorption has no influence on the adsorption kinetics. To determine the effective diffusion time constant $D_{\mathrm{e}, \mathrm{IFD}} / r^{2}$, Eq. (21) was fitted to the experimentally determined fractional uptake $F$. Due to the series expansion, no exact analytical solution of Eq. (21) is feasible. Thus, terms up to $n=10$ were considered in the calculations since no influence of the higher terms on the fitting procedure was observed.
Table 7 Adsorption loadings $q$ of M2 with the respective combined expanded uncertainty $U_{\mathrm{c}}$ for $k=2$

\begin{tabular}{|c|c|c|c|c|c|}
\hline$T_{\text {ads }}[\mathrm{K}]$ & $T_{\mathrm{VLE}}[\mathrm{K}]$ & $p[\mathrm{kPa}]$ & $p / p_{0}{ }^{\mathrm{a}}[-]$ & $q[\mathrm{mmol} / \mathrm{g}]$ & $U_{\mathrm{c}}(q)[\mathrm{mmol} / \mathrm{g}]$ \\
\hline \multicolumn{6}{|l|}{$298 \mathrm{~K}$} \\
\hline 297.87 & 263.24 & 2.2639 & 0.135 & 5.188 & 0.022 \\
\hline 297.86 & 268.32 & 3.1187 & 0.186 & 6.610 & 0.023 \\
\hline 297.87 & 273.33 & 4.2657 & 0.255 & 8.057 & 0.024 \\
\hline 297.87 & 278.29 & 5.7392 & 0.343 & 9.270 & 0.024 \\
\hline 297.87 & 283.24 & 7.6349 & 0.456 & 10.229 & 0.024 \\
\hline 297.79 & 288.22 & 10.116 & 0.607 & 10.893 & 0.025 \\
\hline 297.83 & 293.15 & 13.257 & 0.794 & 11.315 & 0.025 \\
\hline 297.90 & 295.66 & 14.886 & 0.888 & 11.511 & 0.025 \\
\hline 297.88 & 296.66 & 15.688 & 0.937 & 11.662 & 0.025 \\
\hline \multicolumn{6}{|l|}{$318 \mathrm{~K}$} \\
\hline 317.80 & 263.28 & 2.2632 & 0.051 & 1.876 & 0.021 \\
\hline 317.80 & 268.23 & 3.0988 & 0.070 & 2.470 & 0.021 \\
\hline 317.76 & 273.26 & 4.2378 & 0.097 & 3.248 & 0.022 \\
\hline 317.85 & 278.21 & 5.7157 & 0.130 & 4.209 & 0.022 \\
\hline 317.85 & 283.26 & 7.6905 & 0.175 & 5.426 & 0.023 \\
\hline 317.83 & 288.17 & 10.163 & 0.231 & 6.706 & 0.023 \\
\hline 317.88 & 293.11 & 13.328 & 0.302 & 7.979 & 0.024 \\
\hline 317.95 & 298.24 & 17.422 & 0.394 & 9.107 & 0.024 \\
\hline 317.90 & 303.19 & 22.325 & 0.506 & 9.976 & 0.024 \\
\hline 318.05 & 308.20 & 28.425 & 0.640 & 10.584 & 0.025 \\
\hline 318.50 & 313.21 & 35.720 & 0.788 & 10.962 & 0.025 \\
\hline 318.71 & 315.60 & 40.080 & 0.875 & 11.180 & 0.025 \\
\hline 318.45 & 316.59 & 41.586 & 0.919 & 11.346 & 0.025 \\
\hline 318.55 & 317.57 & 43.775 & 0.963 & 11.622 & 0.025 \\
\hline \multicolumn{6}{|c|}{$318 \mathrm{~K}$-reproduced } \\
\hline 317.79 & 293.29 & 13.370 & 0.304 & 8.062 & 0.024 \\
\hline 317.89 & 298.31 & 17.490 & 0.396 & 9.170 & 0.024 \\
\hline 318.03 & 303.21 & 21.992 & 0.495 & 9.938 & 0.024 \\
\hline 318.01 & 308.21 & 28.481 & 0.642 & 10.612 & 0.025 \\
\hline 318.41 & 313.22 & 35.680 & 0.790 & 10.990 & 0.025 \\
\hline 318.64 & 315.60 & 39.807 & 0.872 & 11.180 & 0.025 \\
\hline
\end{tabular}

${ }^{\text {a }}$ The saturated vapor pressure $p_{0}$ was calculated for pure methanol with $T_{\text {ads }}$ for each measuring point with the EOS byde Reuck and Craven [6]

$F=1-\frac{6}{\pi^{2}} \cdot \sum_{n=1}^{\infty} \frac{1}{n^{2}} \cdot \mathrm{e}^{-\frac{D_{\mathrm{e}, \mathrm{IFD}}}{r^{2}} \cdot n^{2} \cdot \pi^{2} \cdot t}$

The LDF model was formulated by Glueckauf and Coates [31] and describes the adsorption kinetics as a differential equation according to Eq. (22). The solution for an isobaric adsorption process was later developed by Glueckauf [32] and is given in Eq. (23) as a simple exponential function. The fractional uptake is expressed in terms of the mass transfer coefficient $k_{\mathrm{LDF}}$. As discussed by Glueckauf [32] and Ruthven [33], a relation exists between $k_{\mathrm{LDF}}$ and $D_{\mathrm{e}, \mathrm{IFD}}$ according to Eq. (24), for which a value of 
$\Omega=15$ was suggested as a first approximation. However, it is already known that $\Omega$ depends on $T, p$, and $t$ and therefore differs from the value of 15 [21,34].

$\frac{\partial q(t)}{\partial t}=k_{\mathrm{LDF}} \cdot\left[q_{\mathrm{eq}}-q(t)\right]$

$F=1-\mathrm{e}^{-t \cdot k_{\mathrm{LDF}}}$

$\Omega=\frac{k_{\mathrm{LDF}}}{D_{\mathrm{e}, \mathrm{IFD}} / r^{2}}$

The advantage of the two previous models is that they can be adjusted without difficulty. However, heat effects due to the heat of adsorption are neglected. Especially with larger sample quantities, heat effects can have a significant influence on the adsorption kinetics. The experimental data was therefore also used to fit the more comprehensive NFD model according to Eq. 25, which considers heat effects and diffusion limiting bed effects [35]. The constraints are given in Eqs. (26-28), in which $h$ is the heat transfer coefficient between the external surface area $S$ of the adsorbent and the gas phase, $\Delta H$ is the heat of adsorption, $c_{\mathrm{s}}$ and $\rho_{\mathrm{s}}$ are the heat capacity and the density of the adsorbent, and $q^{*}$ is the adsorbed phase concentration at equilibrium state. The number of terms considered for the calculation was also set as $n=10$.

$F=1-\sum_{n=1}^{\infty} \frac{2 \cdot \mathrm{e}^{-b_{n}^{2} \cdot t \cdot D_{\mathrm{e}, \mathrm{NFD}} / r^{2}}}{b_{n}^{2} \cdot \cot \left(b_{n}^{2}\right) \cdot\left(1+\frac{2}{\beta}\right)+b_{n}^{2}+b_{n} \cdot \cot \left(b_{n}\right)}$

$\cot \left(b_{n}\right)=\frac{\beta \cdot b_{n}}{\alpha-b_{n}^{2}}$ $\alpha=\frac{h \cdot S \cdot r^{2}}{\rho \cdot c_{\mathrm{s}} \cdot D_{\mathrm{e}, \mathrm{NFD}}}$

$\beta=\frac{\Delta H}{c_{\mathrm{s}}} \cdot\left(\frac{\partial q^{*}}{\partial T}\right)$

\section{Results and discussion}

\subsection{Equilibrium}

The results of the adsorption equilibria measurements are shown for both methanol samples at temperatures of $298 \mathrm{~K}$ and $318 \mathrm{~K}$ in Fig. 2. The numerical values for the adsorption equilibria with the respective combined expanded uncertainty of the data points are also given in Table 6 for sample M1 and in Table 7 for sample M2. In Fig. 2a, equilibrium loadings are plotted in regard to the absolute pressure, showing a pronounced adsorption for both samples at the lower temperature of $298 \mathrm{~K}$. However, if they are plotted in regard to the respective vapor pressure ratio $p /\left(p_{0}\left(T_{\mathrm{ads}}\right)\right)$ (see Fig. 2b), the differences between the two temperatures become considerably smaller. Regarding the influence of the two methanol samples, no significant difference can be seen in both plots of Fig. 2 .

Nevertheless, by comparing the values listed in Tables 6, 7 , differences between the methanol samples become noticeable. For the measurements conducted with M1 at $318 \mathrm{~K}$ and pressures up to $10 \mathrm{kPa}$, adsorption loadings were found to be $\sim 0.1 \mathrm{mmol} / \mathrm{g}$ higher than for the sample M2, while this deviation is decreasing with a further increase in pressure. Although the deviation seems to be small, they lie outside of the determined measurement uncertainty range and, e.g.,
Fig. 2 Adsorption equilibria loadings for both methanol samples (M1 and M2), determined isothermally at $298 \mathrm{~K}$ and 318 K. Data are shown in regard to absolute pressure $p$ (a) and vapor pressure ratio $p / p_{0}(\mathbf{b})$ (a)

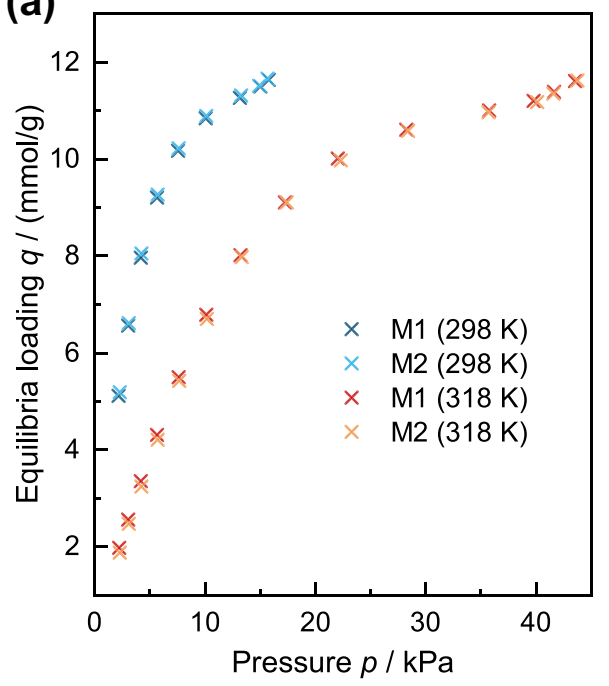

(b)

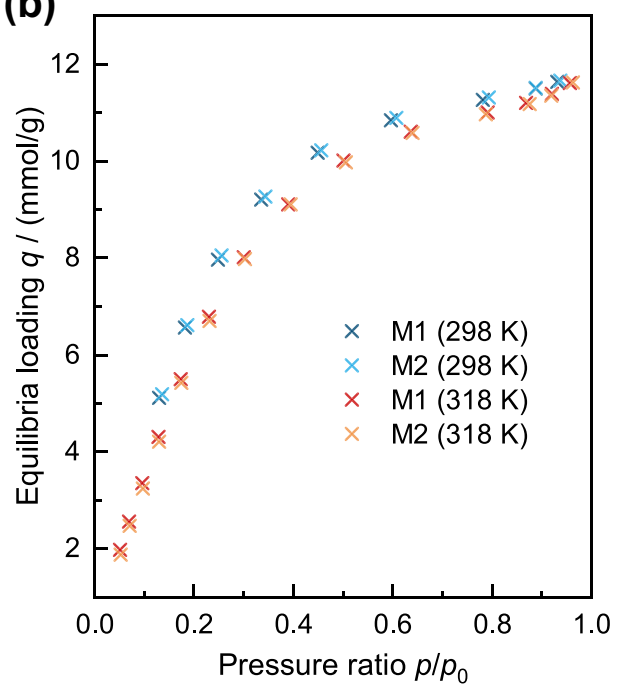


result in relative deviations of up to $5 \%$ for the measurements at $2 \mathrm{kPa}$ and $3 \mathrm{kPa}$. Besides, it should be noted that the pressure for the measurements with $\mathrm{M} 1$ was in general slightly lower than with M2, which should actually result in lower adsorption loadings for sample M1. The repeated measurements at $318 \mathrm{~K}$ show that the data is reproducible. Deviations observed for repeated measurements are within the calculated measurement uncertainty or can be explained by slight differences in pressure. For the adsorption measurements at $298 \mathrm{~K}$, adsorption loadings were found to be (0.04-0.08) $\mathrm{mmol} / \mathrm{g}$ higher for the M2 sample. Due to higher adsorption at $298 \mathrm{~K}$, the resulting relative deviations are below $1.4 \%$. But in this case, the deviation can be explained by slightly higher pressures at the measurements with M2 (see Fig. 2).

The differences might be related to two different effects. On the one hand, the true saturated vapor pressure $p_{0}$ of both samples may differ from the value calculated with the EOS. Since both samples contain different amounts of water,

Table 8 Results for the best-fit parameters of the isotherm model by Dubinin and Astakhov

\begin{tabular}{llllll}
\hline Sample & $T_{\text {ads }}[\mathrm{K}]$ & $v_{0}\left[\mathrm{~cm}^{3} / \mathrm{g}\right]$ & $E[\mathrm{~J} / \mathrm{mol}]$ & $n[-]$ & RMSD [-] \\
\hline M1 & 298.03 & 0.475 & 5606 & 1.951 & 0.00689 \\
M1 & 318.08 & 0.481 & 5578 & 1.679 & 0.00911 \\
M2 & 297.86 & 0.469 & 5537 & 2.061 & 0.00291 \\
M2 & 318.08 & 0.479 & 5479 & 1.706 & 0.00899 \\
\hline
\end{tabular}

the true values of both samples are different (cf. Table 1), leading to a shifted $\mathrm{x}$-axis in Fig. 2b. On the other hand, the adsorption of water might have a stronger temperature dependence than the adsorption of pure methanol, resulting in more pronounced deviations at the higher measurement temperature.

The adsorption data sets were used to adapt the DubininAstakhov isotherm model. Since the model requires a constant adsorption temperature, the arithmetic temperature mean of the data points was used and the resulting best-fit parameters for the pore volume $v_{0}$, the characteristic energy of adsorption $E$, and the Dubinin coefficient $n$ are given in Table 8 . The deviations of values for $v_{0}$ and $E$ for both methanol samples differ only slightly, but at both temperatures, the values for M2 are smaller. For the Dubinin coefficient, the deviations are more pronounced, especially comparing the parameters for $298 \mathrm{~K}$. With values for the pore volume $v_{0}$ between $0.469 \mathrm{~cm}^{3} / \mathrm{g}$ and $0.481 \mathrm{~cm}^{3} / \mathrm{g}$, the results are quite close to the values of the $\mathrm{N}_{2}$-BET analysis $\left(0.491 \mathrm{~cm}^{3} / \mathrm{g}\right)$ and the $\mathrm{CO}_{2}$-DA analysis $\left(0.457 \mathrm{~cm}^{3} / \mathrm{g}\right)$, and slightly higher than the NLDFT result $\left(0.428 \mathrm{~cm}^{3} / \mathrm{g}\right)$. The overall good agreement with these data confirms the reliability of the methanol measurement data.

\subsection{Kinetics}

The kinetics of adsorption were recorded for the different adsorption measurements. For most of the adsorption experiments, the kinetics could be analyzed and compared.

Table 9 Effective diffusion time constants $D_{\mathrm{e}, \mathrm{IFD}} / r^{2}$ for the isothermal model, mass transfer coefficients $k_{\mathrm{LDF}}$, and effective diffusion time constants $D_{\mathrm{e}, \mathrm{NFD}} / r^{2}$ for the nonisothermal model for both methanol samples at various temperatures and pressures

\begin{tabular}{|c|c|c|c|c|c|c|c|c|c|}
\hline \multicolumn{5}{|c|}{ Methanol sample M1 } & \multicolumn{5}{|c|}{ Methanol sample M2 } \\
\hline$T_{\text {ads }}[\mathrm{K}]$ & $p / p_{0}{ }^{\mathrm{a}}[-]$ & $\begin{array}{l}D_{\mathrm{e}, \mathrm{IFD}} / r^{2} \\
{\left[10^{-5} 1 / \mathrm{s}\right]}\end{array}$ & $k_{\mathrm{LDF}}\left[10^{-4} \cdot 1 / \mathrm{s}\right]$ & $\begin{array}{l}D_{\mathrm{e}, \mathrm{NFD}} / r^{2} \\
{\left[10^{-4} 1 / \mathrm{s}\right]}\end{array}$ & $T_{\text {ads }}[\mathrm{K}]$ & $p / p_{0}{ }^{\mathrm{a}}[-]$ & $\begin{array}{l}D_{\mathrm{e}, \mathrm{IFD}} / r^{2} \\
{\left[10^{-5} \cdot 1 / \mathrm{s}\right]}\end{array}$ & $k_{\mathrm{LDF}}\left[10^{-4} \cdot 1 / \mathrm{s}\right]$ & $\begin{array}{l}D_{\mathrm{e}, \mathrm{NFD}} / r^{2} \\
{\left[10^{-4} \cdot 1 / \mathrm{s}\right]}\end{array}$ \\
\hline 297.98 & 0.182 & 1.55 & 4.49 & 4.55 & 297.86 & 0.186 & 1.03 & 3.53 & 2.80 \\
\hline 297.98 & 0.248 & 1.80 & 4.94 & 5.60 & 297.87 & 0.255 & 1.40 & 4.26 & 3.42 \\
\hline 298.02 & 0.335 & 2.39 & 5.89 & 9.20 & 297.87 & 0.343 & 1.84 & 5.01 & 6.23 \\
\hline 297.99 & 0.449 & 3.61 & 7.67 & 16.92 & 297.87 & 0.456 & 2.62 & 6.23 & 11.43 \\
\hline 298.04 & 0.596 & 6.29 & 11.43 & 21.69 & 297.79 & 0.607 & 5.44 & 10.25 & 14.37 \\
\hline 298.04 & 0.781 & 9.74 & 16.41 & 26.85 & 297.83 & 0.794 & 8.14 & 14.11 & 17.07 \\
\hline 317.83 & 0.069 & 4.55 & 8.98 & 21.60 & 317.80 & 0.070 & 2.93 & 6.64 & 12.98 \\
\hline 317.79 & 0.095 & 4.30 & 8.64 & 19.20 & 317.76 & 0.097 & 2.99 & 6.79 & 12.75 \\
\hline 317.80 & 0.129 & 3.43 & 7.43 & 12.35 & 317.85 & 0.130 & 2.63 & 6.24 & 8.75 \\
\hline 317.86 & 0.173 & 2.97 & 6.76 & 11.21 & 317.85 & 0.175 & 2.32 & 5.78 & 5.66 \\
\hline 317.81 & 0.230 & 2.82 & 6.55 & 10.79 & 317.83 & 0.231 & 2.41 & 5.92 & 7.61 \\
\hline 317.86 & 0.300 & 3.40 & 7.38 & 14.90 & 317.88 & 0.302 & 2.91 & 6.68 & 11.10 \\
\hline 317.96 & 0.389 & 4.24 & 8.58 & 20.58 & 317.95 & 0.394 & 3.94 & 8.16 & 15.10 \\
\hline 317.86 & 0.500 & 5.80 & 10.73 & 22.68 & 317.90 & 0.506 & 5.58 & 10.44 & 16.82 \\
\hline 317.99 & 0.636 & 8.98 & 15.42 & 28.01 & 318.05 & 0.640 & 8.42 & 14.43 & 22.11 \\
\hline
\end{tabular}

${ }^{\text {a }}$ The saturated vapor pressure $p_{0}$ was calculated for pure methanol with $T_{\text {ads }}$ for each measuring point with the EOS byde Reuck and Craven [6] 
An overview of the evaluated kinetics can be found in Table 9, in which the effective diffusion time constants $D_{\mathrm{e}} / \mathrm{r}^{2}$ and the mass transfer coefficients $k_{\mathrm{LDF}}$ for the different measurements are listed. Due to different reasons, the kinetics of a few measurements could not be properly analyzed. The measurements for the first value of each isotherm were started at an evacuated state in the measuring cell and by cooling down the VLE cell, thus, the data is not comparable with the other measurements. For the last two measurements at $298 \mathrm{~K}$ and the last four measurements at $318 \mathrm{~K}$, the difference between $T_{\text {ads }}$ and $T_{\mathrm{VLE}}$ was rather small, which has led to discontinuities during the increase of pressure and mass. Therefore, no continuous kinetic curve could be recorded and the data were also not comparable to the other measurements. For the kinetic curve at $p / p_{0}=0.504$ at $318 \mathrm{~K}$, a continuous data evaluation was also not possible, thus, the data from the reproduced measurement series were taken for comparison.

The time-dependent fractional uptake (see Eq. 17) is shown for different pressures at $298 \mathrm{~K}$ and $318 \mathrm{~K}$ in Fig. 2. In all cases, the fractional uptake of sample M1 increases faster than of sample M2. With increasing pressure, the
Fig. 3 Fractional uptake curves with a logarithmic time scale for the two methanol samples at different temperature and pressure conditions: $\mathbf{a} T_{\mathrm{ads}}=298 \mathrm{~K}$ and $p \approx 3 \mathrm{kPa}, \mathbf{b} T_{\text {ads }}=318 \mathrm{~K}$ and $p \approx 3 \mathrm{kPa}, \mathbf{c} T_{\mathrm{ads}}=298 \mathrm{~K}$ and $p \approx 8 \mathrm{kPa}, \mathbf{d} T_{\mathrm{ads}}=318 \mathrm{~K}$ and $p \approx 8 \mathrm{kPa}, \mathbf{e} T_{\text {ads }}=298 \mathrm{~K}$ and $p \approx 13 \mathrm{kPa}, \mathbf{f} T_{\text {ads }}=318 \mathrm{~K}$ and $p \approx 13 \mathrm{kPa}$, and $\mathbf{g}$

$T_{\text {ads }}=318 \mathrm{~K}$ and $p \approx 22 \mathrm{kPa}$
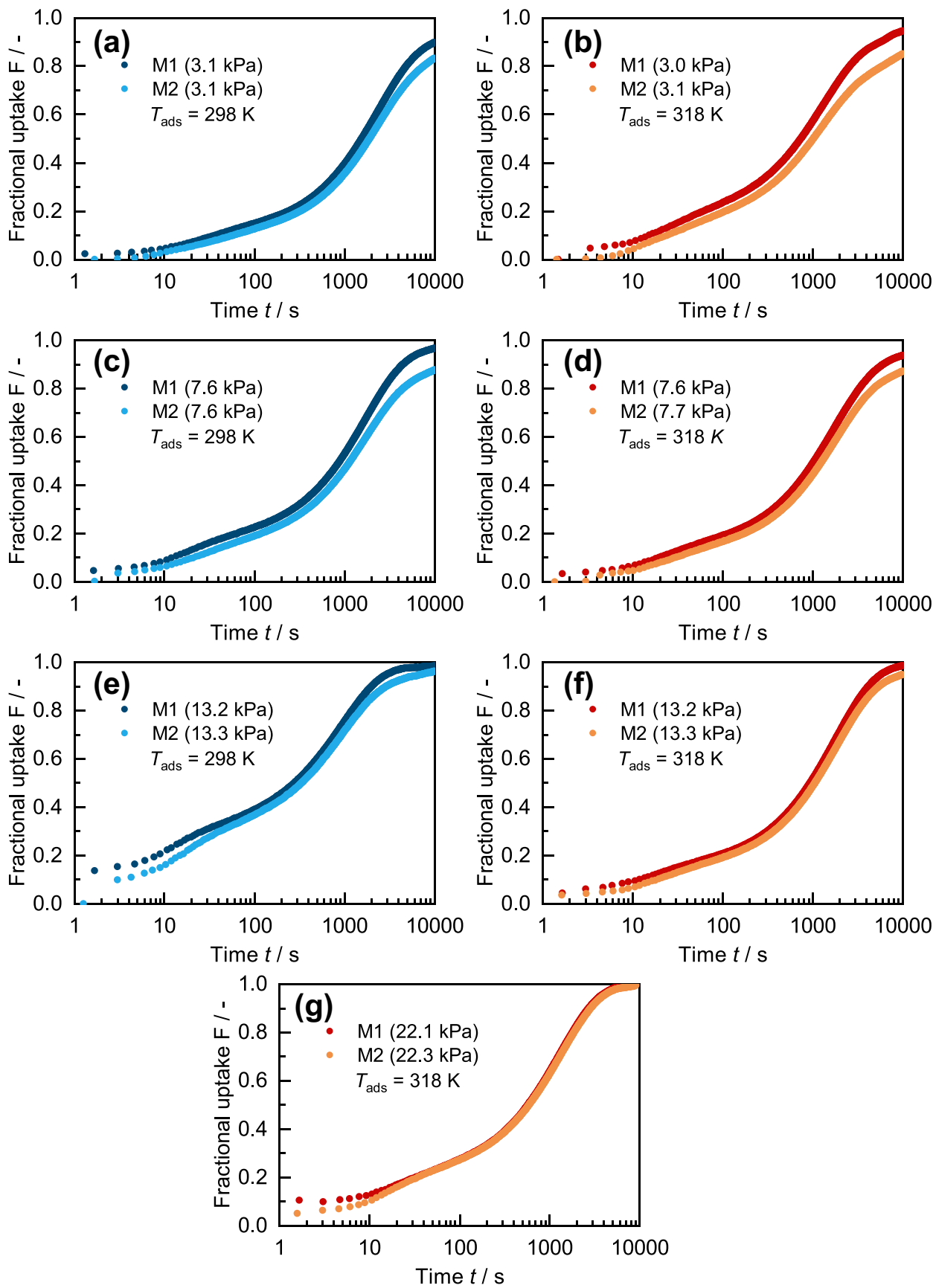

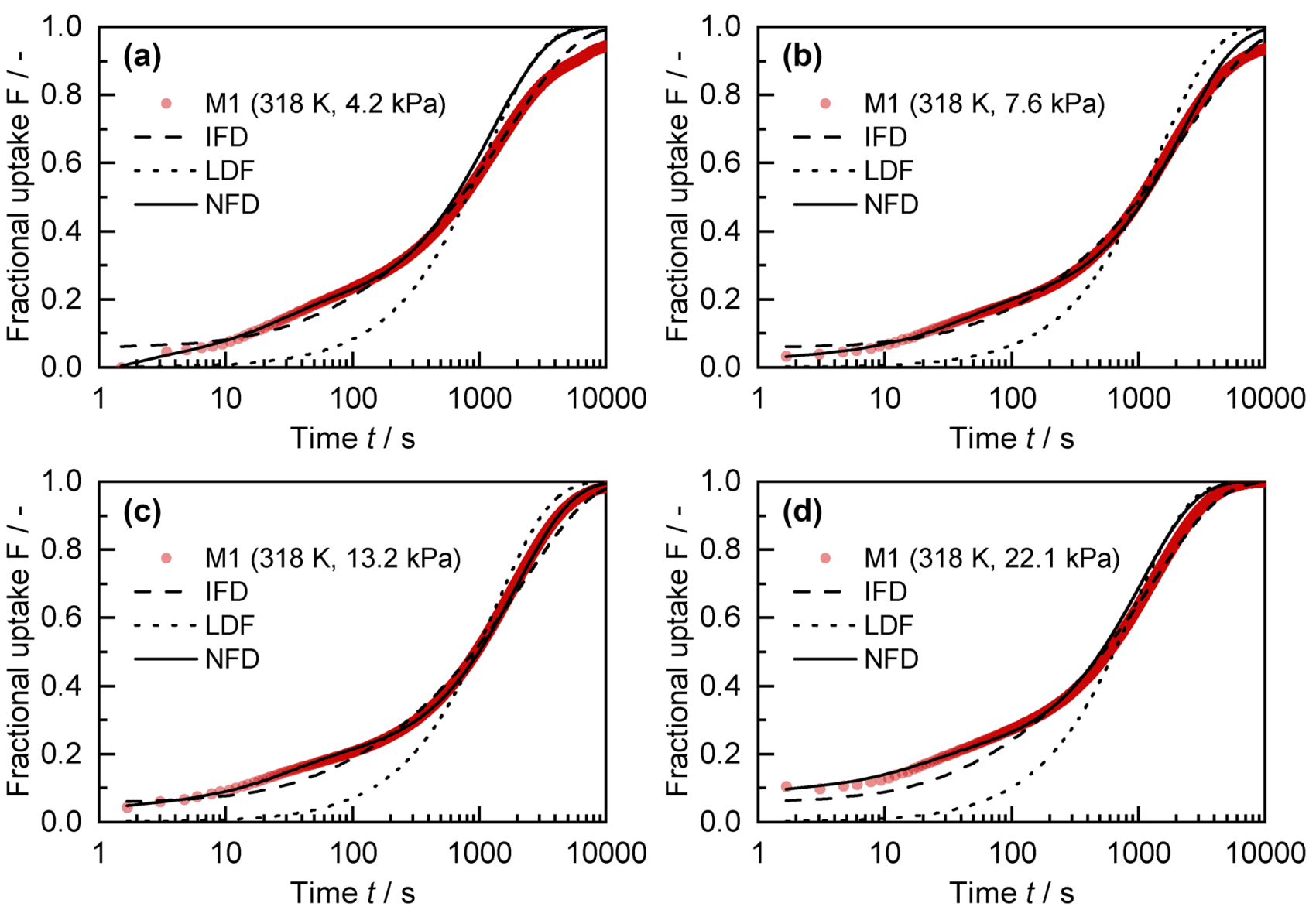

Fig. 4 Modeled kinetic curves using the isothermal model (IFD), the linear driving force model (LDF), and the nonisothermal model (NFD) compared with the experimental data for the sample M1 at

$T_{\mathrm{ads}}=318 \mathrm{~K}$ and $p \approx 4.2 \mathrm{kPa}(\mathbf{a}), p \approx 7.6 \mathrm{kPa}(\mathbf{b}), p \approx 13.2 \mathrm{kPa}(\mathbf{c})$, and $p \approx 22.1 \mathrm{kPa}(\mathbf{d})$

kinetics become in general faster and at the same time the differences between the two samples decrease. The faster kinetics can be explained due to the decreasing values for the adsorption loading differences $\Delta q$ between the individual pressure steps since less additional adsorption takes place. However, the kinetics at a temperature of $318 \mathrm{~K}$ and a pressure of $7.6 \mathrm{kPa}$ and $7.7 \mathrm{kPa}$, respectively (Fig. 3d), show a slower increase than for the pressure of $3.0 \mathrm{kPa}$ and $3.1 \mathrm{kPa}$, respectively (see Fig. 3b).

The kinetic data were used to adjust the isothermal Fickian diffusion model (IFD), the linear driving force model (LDF), and the nonisothermal Fickian diffusion model (NFD). For the adsorption of the sample M1 at $318 \mathrm{~K}$, the modeled curves are exemplarily shown for four pressure points in Fig. 4. It can be seen clearly that the LDF model describes the adsorption kinetics by far the worst. The model significantly underestimates the kinetics in the first $500 \mathrm{~s}$; subsequently, it overestimates the kinetics and reaches the adsorption equilibrium too early.

The IFD and the NFD models describe the kinetics more accurately, but both show different characteristics. The NFD

model describes the course of the first $1000 \mathrm{~s}$ accurately, while the IFD model shows there some deviations. Since a relatively large sample mass was used for the experiments (see Table 4) and the adsorbed loading is quite large, it can be assumed that the heat of adsorption and the sample loading have a significant influence on the adsorption kinetics. The comparatively strong increase at the beginning of the adsorption process strengthens this assumption. Therefore, the NFD model can describe the initial phase much more accurately than the IFD model. As time progresses $(t>1000 \mathrm{~s})$, the goodness of fit of the IFD model improves. Since the adsorption is less pronounced with increasing time, the heat of adsorption also decreases; thus, the later course of the adsorption kinetics can be well described by the isothermal IFD model, whereas the NFD model partially reaches the adsorption equilibrium too early.

As a result of the kinetic modeling, effective diffusion time constants and mass transfer coefficients were obtained, which are shown in Fig. 5 in regard to the pressure ratio $p / p_{0}$. These values confirm the observations regarding the differences between the two methanol 

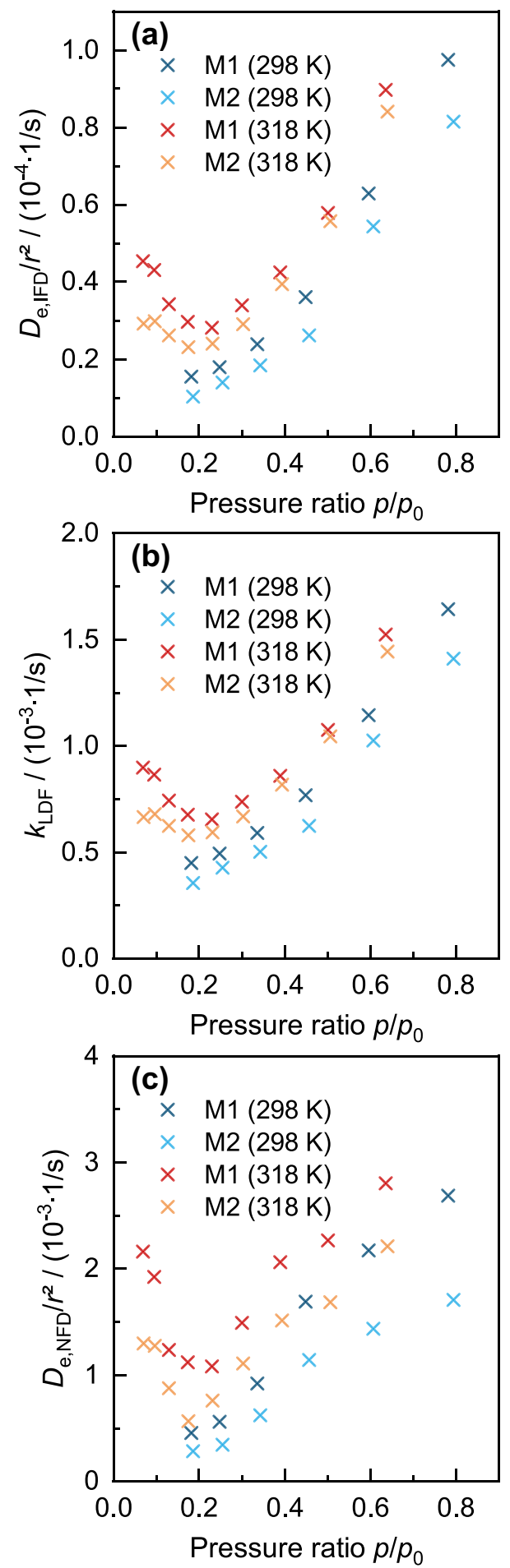

Fig. 5 Effective diffusion time constants $D_{\mathrm{e}, \mathrm{IFD}} / r^{2}$ for the isothermal model (a), mass transfer coefficients $k_{\mathrm{LDF}}(\mathbf{b})$, and effective diffusion time constants $D_{\mathrm{e}, \mathrm{NFD}} / r^{2}$ for the nonisothermal model (c) in regard to the vapor pressure ratio $p / p_{0}$ for both methanol samples at $298 \mathrm{~K}$ and $318 \mathrm{~K}$ samples from the kinetic plots in Fig. 3 since the values for $D_{\mathrm{e}, \mathrm{IFD}} / r^{2}, k_{\mathrm{LDF}}$, and $D_{\mathrm{e}, \mathrm{NFD}} / r^{2}$ are higher for the purer methanol sample M1. The values for $D_{\mathrm{e}, \mathrm{IFD}} / r^{2}$ are up to $55 \%$ higher for sample $\mathrm{M} 1$ than for $\mathrm{M} 2$, and the values for $k_{\mathrm{LDF}}$ and $D_{\mathrm{e}, \mathrm{NFD}} / r^{2}$ are up to $35 \%$ and $98 \%$ higher, respectively. For both temperatures, a consistently faster kinetic is found for M1 than for M2 and the differences are in general more pronounced for the kinetics at $298 \mathrm{~K}$. Since the LDF model poorly reproduced the experimental data, the values for $k_{\mathrm{LDF}}$ should be taken with caution. Nevertheless, the mass transfer coefficients show with respect to temperature dependence, pressure dependence, and sample purity a similar course as the effective diffusion time constants.

In general, higher effective diffusion time constants and mass transfer coefficients were obtained at the higher temperature of $318 \mathrm{~K}$, which agrees with the temperature dependence of the well-known kinetic theory of gases. Regarding the pressure dependence, a more complex behavior with increasing pressures was observed since up to $p / p_{0}=0.2$ the values for the kinetic parameters at $318 \mathrm{~K}$ decrease with increasing pressure; at higher relative pressure they increase with pressure. For the measurements at $298 \mathrm{~K}$ only one measurement with a pressure ratio below 0.2 was evaluable, thus, this pressure behavior cannot be confirmed based on these data. However, a decrease of the kinetic parameter is not to be expected since in this pressure range the adsorption isotherms have an almost linear course (see Fig. 2). The decrease might indicate that the high sample mass affects the adsorption kinetics even more than can be compensated by the NFD model. This should be investigated in more detail in future experiments with different sample masses, as suggested in the comprehensive review by Wang et al. [36]. Nevertheless, different slopes for the pressure dependence of effective diffusion time constants or mass transfer coefficient were reported in the literature for a variety of gases, but to the best of our knowledge, no study on the dependence of methanol exists for comparison. As some examples, Bae and Lee [37], Saha and Deng [38], Wedler et al. [39], and Maghsoudi et al. [40] measured values increasing with increasing pressure for $\mathrm{N}_{2}, \mathrm{O}_{2}, \mathrm{Ar}, \mathrm{CO}, \mathrm{CO}_{2}, \mathrm{CH}_{4}, \mathrm{SO}_{2}, \mathrm{NH}_{3}$, $\mathrm{C}_{3} \mathrm{H}_{8} \mathrm{O}_{2}$, and $\mathrm{C}_{3} \mathrm{H}_{8}$, but decreasing values were obtained by Zhang et al. [41], Saha and Deng [38], and Yang and Liu [42] for $\mathrm{CO}_{2}, \mathrm{CH}_{4}$, and $\mathrm{N}_{2} \mathrm{O}$. No consistent slope for the pressure dependence of $\mathrm{N}_{2}, \mathrm{CO}, \mathrm{CO}_{2}$, and $\mathrm{CH}_{4}$ was observed by Xiao et al. [43] and Park et al. [44]. However, the studies mostly investigated very limited absolute pressure ranges and did not analyze them with respect to the $p / p_{0}$ ratio. Furthermore, in some of the studies, it is not traceably described whether cumulative measurements or measurements starting from vacuum were performed. Both could be a reason for the differing behavior of gases (e.g., for $\mathrm{CO}_{2}$ and $\mathrm{CH}_{4}$ ) between the studies. The results in Fig. 5 
show that the different observations in literature might be explained by different investigated pressure ranges and it becomes apparent that the pressure dependence of kinetic adsorption parameters should be investigated over a wide $p / p_{0}$ range.

\section{Conclusions}

The measurements with two different methanol samples within this study show that adsorption equilibria and in particular adsorption kinetics are influenced by the water content of the chosen methanol sample. By comparing adsorption equilibrium isotherms for methanol samples with a purity of $99.9 \%$ and $98.5 \%$, deviations for the adsorbed equilibrium loading of up to $5 \%$ were found between both samples. For the adsorption kinetics, the differences between the two samples become even more obvious. The kinetics of the less pure methanol sample M2 are noticeably slower, as shown by the curves of the fractional uptake. The effective diffusion time constants $D_{\mathrm{e}, \mathrm{IFD}} / r^{2}$ and $D_{\mathrm{e}, \mathrm{NFD}} / r^{2}$ determined by the IFD and NFD model and the mass transfer coefficient $k_{\mathrm{LDF}}$ determined by the LDF model are significantly higher for the purer sample $\mathrm{M} 1$; for $D_{\mathrm{e}, \mathrm{IFD}} / r^{2}$ up to $55 \%$, for $D_{\mathrm{e}, \mathrm{NFD}} / r^{2}$ up to $98 \%$, and for $k_{\mathrm{LDF}}$ up to $35 \%$. However, the LDF model could only poorly describe the experimental data of the adsorption kinetics; the results of the IFD and NFD models were more accurate. Especially in the first $1000 \mathrm{~s}$, the NFD model was able to describe the kinetics most accurately since the released heat of adsorption is considered within the model.

The equilibrium and the kinetic results prove that samples should be used as pure as possible, otherwise significant deviations can occur due to the presence of water, which has an impact on the design of the industrial adsorption process. The following two reasons for the deviations should be considered: (a) the water in the sample has different adsorption behavior than pure methanol in regard to adsorption kinetics and temperature and pressure dependence and (b) the true saturated vapor pressure $p_{0}$ of the samples differ from each other (cf. Table 1) and lead to an incorrect interpretation of the adsorption isotherms. In the future, further studies on the influence of sample purity and water content should be performed using other fluids with low dew points such as toluene, ethanol, or acetone.

In addition to the investigations on the influence of sample purity, the pressure dependence of the kinetic parameters was studied. In literature, the pressure dependence is described in a supposedly contradictory manner, increasing, and decreasing kinetic values with rising pressure are reported. The results from this study showed for $p / p_{0}$ below 0.2 decreasing values for the kinetic parameter and increasing parameters with increasing pressure. However, the decrease at the low pressures was actually not to be expected since the adsorption isotherms in this pressure range show a linear course. In future studies, the pressure dependence of the kinetic parameters should be further investigated using varying sample masses, to avoid the possible influence of heat and bed effects.

Acknowledgements We thank Roland Span for providing the resources for the investigations. We also thank Christin Pflieger and Martin Muhler for the GC analysis of the two methanol samples.

Author contribution MR: investigation, formal analysis, data curation, writing-original draft. CW: investigation, methodology, conceptualization, validation, visualization, supervision, project administration, writing—original draft, writing—review and editing.

Funding Open Access funding enabled and organized by Projekt DEAL.

Data availability Adsorption data is given in the manuscript.

\section{Declarations}

Conflict of interest The author declare that they have no conflict of interest.

Open Access This article is licensed under a Creative Commons Attribution 4.0 International License, which permits use, sharing, adaptation, distribution and reproduction in any medium or format, as long as you give appropriate credit to the original author(s) and the source, provide a link to the Creative Commons licence, and indicate if changes were made. The images or other third party material in this article are included in the article's Creative Commons licence, unless indicated otherwise in a credit line to the material. If material is not included in the article's Creative Commons licence and your intended use is not permitted by statutory regulation or exceeds the permitted use, you will need to obtain permission directly from the copyright holder. To view a copy of this licence, visit http://creativecommons.org/licenses/by/4.0/.

\section{References}

1. Ushiki, I., Ota, M., Sato, Y., Inomata, H.: Prediction of VOCs adsorption equilibria on activated carbon in supercritical carbon dioxide over a wide range of temperature and pressure by using pure component adsorption data: Combined approach of the Dubinin-Astakhov equation and the non-ideal adsorbed solution theory (NIAST). Fluid Phase Equilib. 375, 293-305 (2014). https://doi.org/10.1016/j.fluid.2014.05.004

2. Choudhury, B., Saha, B.B., Chatterjee, P.K., Sarkar, J.P.: An overview of developments in adsorption refrigeration systems towards a sustainable way of cooling. Appl. Energy 104, 554-567 (2013). https://doi.org/10.1016/j.apenergy.2012.11.042

3. Yang, X., Kleinrahm, R., McLinden, M.O., Richter, M.: Uncertainty analysis of adsorption measurements using commercial gravimetric sorption analyzers with simultaneous density measurement based on a magnetic-suspension balance. Adsorption (2020). https://doi.org/10.1007/s10450-020-00236-1

4. Rother, J., Fieback, T., Seif, R., Dreisbach, F.: Characterization of solid and liquid sorbent materials for biogas purification by using 
a new volumetric screening instrument. Rev. Sci. Instrum. 83(5), 55112 (2012). https://doi.org/10.1063/1.4717681

5. Wedler, C., Lotz, K., Arami-Niya, A., Xiao, G., Span, R., Muhler, M., May, E.F., Richter, M.: Influence of mineral composition of chars derived by hydrothermal carbonization on sorption behavior of CO2, CH4, and O2. ACS Omega 5(19), 10704-10714 (2020). https://doi.org/10.1021/acsomega.9b04370

6. de Reuck, K.M., Craven, R.J.B.: International thermodynamic tables of the fluid state-12: Methanol. IUPAC chemical data series, Nr.12. Blackwell Scientific Publications, Oxford (1993)

7. Lemmon, E.W., Bell, I.H., Huber, M.L., McLinden, M.O.: NIST Standard Reference Database 23: Reference fluid thermodynamic and transport properties-REFPROP, version 10.0, National Institute of Standards and Technology (2018)

8. Anderson, C.J., Tao, W., Scholes, C.A., Stevens, G.W., Kentish, S.E.: The performance of carbon membranes in the presence of condensable and non-condensable impurities. J. Membr. Sci. 378(1-2), 117-127 (2011). https://doi.org/10.1016/j.memsci. 2011.04.058

9. Bahamon, D., Díaz-Márquez, A., Gamallo, P., Vega, L.F.: Energetic evaluation of swing adsorption processes for $\mathrm{CO} 2$ capture in selected MOFs and zeolites: Effect of impurities. Chem. Eng. J. 342, 458-473 (2018). https://doi.org/10.1016/j.cej.2018.02.094

10. Passos, E., Meunier, F., Gianola, J.C.: Thermodynamic performance improvement of an intermittent solar-powered refrigeration cycle using adsorption of methanol on activated carbon. Heat Recovery Syst. 6(3), 259-264 (1986)

11. Wu, J.W., Madani, S.H., Biggs, M.J., Phillip, P., Lei, C., Hu, E.J.: Characterizations of activated carbon-methanol adsorption pair including the heat of adsorptions. J. Chem. Eng. Data 60(6), 1727-1731 (2015). https://doi.org/10.1021/je501113y

12. Brunauer, S., Emmett, P.H., Teller, E.: Adsorption of gases in multimolecular layers. J. Am. Chem. Soc. 60(2), 309-319 (1938)

13. Dubinin, M.M., Astakhov, V.A.: Development of the concepts of volume filling of micropores in the adsorption of gases and vapors by microporous adsorbents: COMMUNICATION 1. Carbon adsorbents. Russ. Chem. Bull. 20(1), 3-7 (1971). https://doi. org/10.1007/BF00849307

14. Medek, J.: Possibility of micropore analysis of coal and coke from the carbon dioxide isotherm. Fuel 56(2), 131-133 (1977). https:// doi.org/10.1016/0016-2361(77)90131-4

15. Wedler, C., Span, R.: Micropore analysis of biomass chars by $\mathrm{CO}$ 2 adsorption: Comparison of different analysis methods. Energy Fuels (2021). https://doi.org/10.1021/acs.energyfuels.1c00280

16. Jagiello, J., Kenvin, J., Celzard, A., Fierro, V.: Enhanced resolution of ultra micropore size determination of biochars and activated carbons by dual gas analysis using $\mathrm{N} 2$ and $\mathrm{CO} 2$ with 2D-NLDFT adsorption models. Carbon 144, 206-215 (2019). https://doi.org/10.1016/j.carbon.2018.12.028

17. Jagiello, J., Olivier, J.P.: 2D-NLDFT adsorption models for carbon slit-shaped pores with surface energetical heterogeneity and geometrical corrugation. Carbon 55, 70-80 (2013). https://doi.org/ 10.1016/j.carbon.2012.12.011

18. Jagiello, J., Olivier, J.P.: Carbon slit pore model incorporating surface energetical heterogeneity and geometrical corrugation. Adsorption 19(2-4), 777-783 (2013). https://doi.org/10.1007/ s10450-013-9517-4

19. Scholz, C.W., Frotscher, O., Pohl, S., Span, R., Richter, M.: Measurement and correlation of the (p, $\rho, T)$ behavior of liquid methanol at temperatures from 28315 to $42315 \mathrm{~K}$ and pressures up to $90 \mathrm{MPa}$. Ind. Eng. Chem. Res. 60(9), 3745-3757 (2021). https:// doi.org/10.1021/acs.iecr.0c06248

20. McLinden, M.O., Splett, J.D.: A liquid density standard over wide ranges of temperature and pressure based on toluene. J. Res. Nat.
Inst. Stand. Technol. 113(1), 29-67 (2008). https://doi.org/10. 6028/jres. 113.005

21. Wedler, C., Span, R.: A pore-structure dependent kinetic adsorption model for consideration in char conversion-Adsorption kinetics of $\mathrm{CO} 2$ on biomass chars. Chem. Eng. Sci. 231, 116281 (2021). https://doi.org/10.1016/j.ces.2020.116281

22. Hwang, J., Joss, L., Pini, R.: Measuring and modelling supercritical adsorption of $\mathrm{CO} 2$ and $\mathrm{CH} 4$ on montmorillonite source clay. Microporous Mesoporous Mater. 273, 107-121 (2019). https:// doi.org/10.1016/j.micromeso.2018.06.050

23. Span, R., Beckmüller, R., Hielscher, S., Jäger, A., Mickoleit, E., Neumann, T., Pohl, S., Semrau, B., Thol, M.: TREND thermodynamic reference and engineering data 5.0. Ruhr-Universität Bochum, Lehrstuhl für Thermodynamik (2020)

24. Kleinrahm, R., Yang, X., McLinden, M.O., Richter, M.: Analysis of the systematic force-transmission error of the magneticsuspension coupling in single-sinker densimeters and commercial gravimetric sorption analyzers. Adsorption 25(4), 717-735 (2019). https://doi.org/10.1007/s10450-019-00071-z

25. Lide, D.R. (ed.): CRC handbook of chemistry and physics: A ready-reference book of chemical and physical data, 85 th edn. CRC Press, Boca Raton (2004)

26. Kunz, O., Wagner, W.: The GERG-2008 wide-range equation of state for natural gases and other mixtures: An expansion of GERG-2004. J. Chem. Eng. Data 57(11), 3032-3091 (2012). https://doi.org/10.1021/je300655b

27. ISO/IEC Guide 98-3 Uncertainty of measurement-part 3: Guide to the expression of uncertainty in measurement. International Organization for Standardization (ISO), Geneva (2008)

28. Crank, J.: The mathematics of diffusion, 2nd edn. Clarendon Press, Oxford (1976)

29. Boyd, G.E., Adamson, A.W., Myers, L.S.: The exchange adsorption of ions from aqueous solutions by organic zeolites. II. Kinetics 1. J. Am. Chem. Soc. 69(11), 2836-2848 (1947). https://doi.org/10.1021/ja01203a066

30. Barrer, R.M.: Diffusion in and through solids. Cambridge University Press, Cambridge (1941)

31. Glueckauf, E., Coates, J.I.: Theory of chromatography; the influence of incomplete equilibrium on the front boundary of chromatograms and on the effectiveness of separation. J. Chem. Soc. (1947). https://doi.org/10.1039/JR9470001315

32. Glueckauf, E.: Theory of chromatography. Part 10-Formulæ for diffusion into spheres and their application to chromatography. Trans. Faraday Soc. 51, 1540-1551 (1955). https://doi.org/ 10.1039/TF9555101540

33. Ruthven, D.M.: Principles of adsorption and adsorption processes. A Wiley-interscience publication. Wiley, New York (1984)

34. Sircar, S., Hufton, J.R.: Why does the linear driving force model for adsorption kinetics work? Adsorption 6(2), 137-147 (2000). https://doi.org/10.1023/A:1008965317983

35. Ruthven, D.M., Lee, L.-K.: Kinetics of nonisothermal sorption: Systems with bed diffusion control. AIChE J. 27(4), 654-663 (1981). https://doi.org/10.1002/aic.690270418

36. Wang, J.-Y., Mangano, E., Brandani, S., Ruthven, D.M.: A review of common practices in gravimetric and volumetric adsorption kinetic experiments. Adsorption 27(3), 295-318 (2021). https:// doi.org/10.1007/s10450-020-00276-7

37. Bae, Y.-S., Lee, C.-H.: Sorption kinetics of eight gases on a carbon molecular sieve at elevated pressure. Carbon 43(1), 95-107 (2005). https://doi.org/10.1016/j.carbon.2004.08.026

38. Saha, D., Deng, S.: Adsorption equilibrium and kinetics of $\mathrm{CO} 2$, $\mathrm{CH} 4, \mathrm{~N} 2 \mathrm{O}$, and NH3 on ordered mesoporous carbon. J. Colloid. Interface Sci. 345(2), 402-409 (2010). https://doi.org/10.1016/j. jcis.2010.01.076 
39. Wedler, C., Arami-Niya, A., Xiao, G., Span, R., May, E.F., Richter, M.: Gas diffusion and sorption in carbon conversion. Energy Procedia 158, 1792-1797 (2019). https://doi.org/10.1016/j.egypro.2019.01.422

40. Maghsoudi, H., Abdi, H., Aidani, A.: Temperature- and pressuredependent adsorption equilibria and diffusivities of propylene and propane in pure-silica Si-CHA zeolite. Ind. Eng. Chem. Res. 59(4), 1682-1692 (2020). https://doi.org/10.1021/acs.iecr.9b054 51

41. Zhang, Z., Zhang, W., Chen, X., Xia, Q., Li, Z.: Adsorption of $\mathrm{CO} 2$ on zeolite $13 \times$ and activated carbon with higher surface area. Sep. Sci. Technol. 45(5), 710-719 (2010). https://doi.org/10.1080/ 014963909035711

42. Yang, Y., Liu, S.: Estimation and modeling of pressure-dependent gas diffusion coefficient for coal: A fractal theory-based approach. Fuel 253, 588-606 (2019). https://doi.org/10.1016/j.fuel.2019.05. 009

43. Xiao, G., Li, Z., Saleman, T.L., May, E.F.: Adsorption equilibria and kinetics of $\mathrm{CH} 4$ and $\mathrm{N} 2$ on commercial zeolites and carbons. Adsorption 23(1), 131-147 (2017). https://doi.org/10.1007/ s10450-016-9840-7

44. Park, Y., Ju, Y., Park, D., Lee, C.-H.: Adsorption equilibria and kinetics of six pure gases on pelletized zeolite $13 \times$ up to $10 \mathrm{MPa}$ : $\mathrm{CO} 2, \mathrm{CO}, \mathrm{N} 2, \mathrm{CH} 4, \mathrm{Ar}$ and H2. Chem. Eng. J. 292, 348-365 (2016). https://doi.org/10.1016/j.cej.2016.02.046

45. Bandosz, T.J., Jagiełło, J., Schwarz, J.A., Krzyzanowski, A.: Effect of surface chemistry on sorption of water and methanol on activated carbons. Langmuir 12(26), 6480-6486 (1996). https://doi. org/10.1021/la960340r

46. Linders, M.J.G., van den Broeke, L.J.P., Kapteijn, F., Moulijn, J.A., van Bokhoven, J.J.G.M.: Binary adsorption equilibrium of organics and water on activated carbon. AIChE J. 47(8), 1885$1892(2001)$

47. Fletcher, A.J., Cussen, E.J., Prior, T.J., Rosseinsky, M.J., Kepert, C.J., Thomas, K.M.: Adsorption dynamics of gases and vapors on the nanoporous metal organic framework material Ni2(4,4'bipyridine)3(NO3)4: guest modification of host sorption behavior.
J. Am. Chem. Soc. 123(41), 10001-10011 (2001). https://doi.org/ 10.1021/ja0109895

48. Fletcher, A.J., Cussen, E.J., Bradshaw, D., Rosseinsky, M.J., Thomas, K.M.: Adsorption of gases and vapors on nanoporous Ni2(4,4'-Bipyridine)3(NO3)4 metal-organic framework materials templated with methanol and ethanol: structural effects in adsorption kinetics. J. Am. Chem. Soc. 126(31), 9750-9759 (2004). https://doi.org/10.1021/ja0490267

49. Fletcher, A.J., Yüzak, Y., Thomas, K.M.: Adsorption and desorption kinetics for hydrophilic and hydrophobic vapors on activated carbon. Carbon 44(5), 989-1004 (2006). https://doi.org/10.1016/j. carbon.2005.10.020

50. Wang, L.W., Wang, R.Z., Lu, Z.S., Chen, C.J., Wang, K., Wu, J.Y.: The performance of two adsorption ice making test units using activated carbon and a carbon composite as adsorbents. Carbon 44(13), 2671-2680 (2006). https://doi.org/10.1016/j.carbon.2006. 04.013

51. El-Sharkawy, I.I., Hassan, M., Saha, B.B., Koyama, S., Nasr, M.M.: Study on adsorption of methanol onto carbon based adsorbents. Int. J. Refrig. 32(7), 1579-1586 (2009). https://doi.org/10. 1016/j.ijrefrig.2009.06.011

52. Henninger, S.K., Schicktanz, M., Hügenell, P., Sievers, H., Henning, H.-M.: Evaluation of methanol adsorption on activated carbons for thermally driven chillers part I: Thermophysical characterisation. Int. J. Refrig 35(3), 543-553 (2012). https://doi.org/10. 1016/j.ijrefrig.2011.10.004

53. Xiao, Y., He, G., Yuan, M.: Adsorption equilibrium and kinetics of methanol vapor on zeolites $\mathrm{NaX}, \mathrm{KA}$, and $\mathrm{CaA}$ and activated alumina. Ind. Eng. Chem. Res. 57(42), 14254-14260 (2018). https://doi.org/10.1021/acs.iecr.8b04076

54. Gao, M., Li, H., Yang, M., Gao, S., Wu, P., Tian, P., Xu, S., Ye, M., Liu, Z.: Direct quantification of surface barriers for mass transfer in nanoporous crystalline materials. Commun. Chem. (2019). https://doi.org/10.1038/s42004-019-0144-1

Publisher's Note Springer Nature remains neutral with regard to jurisdictional claims in published maps and institutional affiliations. 